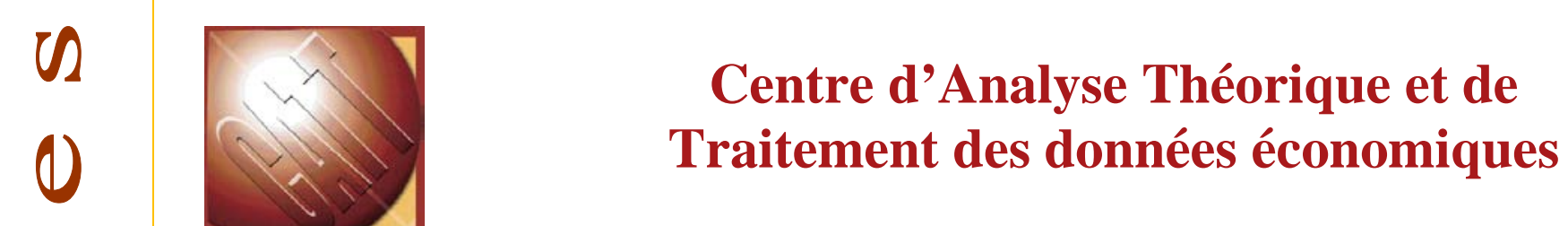

0

CATT WP No. 7

First version: June 2013

Revised: January 2015

SPATIAL DISTRIBUTION

OF SKILLS AND

\title{
REGIONAL TRADE INTEGRATION
}

Fabien CANDAU

Elisa DIENESCH 


\title{
Spatial Distribution of Skills and Regional Trade Integration*
}

\author{
Fabien $\mathrm{CANDAU}^{\dagger} \quad$ Elisa DIENESCH ${ }^{\ddagger}$
}

January 22, 2015

\begin{abstract}
This study is a theoretical and empirical analysis of the effects of regional trade integration on the spatial distribution of skills. We first develop a theoretical model in the economic geography field to integrate heterogeneous workers, housing, local entrepreneurs and skill upgrading by unskilled workers. We then analyse how the domestic integration of each state in the U.S., approximated by truck registrations, influenced the location choice of skilled and unskilled workers in 1940-1960. By using inter- and intrastate trade flow from the U.S. Commodity Flow Survey, we also analyse the impact of regional trade costs for the contemporary period $(1997,2002,2007)$. The theoretical model shows that the bell-shaped curve of spatial development displays a sorting of individuals and firms. Only high-skilled workers increasingly choose the core region during the process of regional integration while intermediate-skilled workers move to the periphery due to the increase in the price of housing. By impacting differently on the opportunity cost to invest in skill acquisition in the core and the periphery, this sorting influences the regional creation of human capital. First a regional divergence in education investment occurs, and then a convergence, but only for high level regional integration. The empirical analysis confirms that regional trade integration has been a determinant of the spatial distribution of skills in the United States.
\end{abstract}

JEL: F12, F66, I21, R23

Keywords: Trade, Education, Spatial Sorting, Migration

\section{Introduction}

This paper examines how regional trade integration influences high- and low- skilled workers to increasingly segregate themselves into different locations. In addition, we aim at understanding how spatial sorting influences incentives to invest in skills for immobile/unskilled workers. Our

\footnotetext{
${ }^{*}$ We thank Antoine Bouët, Patrice Cassagnard, Pierre-Philippe Combes, Matthieu Crozet, José de Sousa, Carl Gaigné, Miren Lafourcade, François Langot, Gianmarco Ottaviano, Serge Rey, Frédéric Robert-Nicoud, Chao Zhang, François-Charles Wolff and participants in the Paris-Sud Seminar for their valuable comments.

${ }^{\dagger}$ fabien.candau@univ-pau.fr

${ }^{\ddagger}$ elisa.dienesch@gmail.com
} 
question is the following: do regional trade costs explain the uneven distribution of human capital between regions?

Economic agglomerations, such as cities and regions, are the main institutions in which not only technological but also social, and sometimes political innovations are developed through market and non-market interactions. Thus the unequal spatial distribution of skills across space can be explained by a myriad of factors linked to the failure or success of these institutions. The heterogeneity of space, such as the geographical advantage of being located at the center of a dynamic country or the disadvantage of being a remote region have been historically significant explaining the spatial inequality of human capital. ${ }^{1}$ Economic forces have taken over from this geographic cause: a large market improves matching between employers and employees, ${ }^{2}$ allows the sharing of facilities, ${ }^{3}$ public and intermediate goods, and improves the creation/transmission of ideas. ${ }^{4}$ Here we focus on pecuniary externalities analysing how imperfect competition interacts with transport costs in order to provide benefits from proximity to market for different kinds of agents. ${ }^{5}$ In brief, this article belongs to the New Economic Geography (NEG) literature that highlights how market size interacts with scale economies internal to firms and transport costs to shape the space-economy by allowing market size to be determined endogenously. By introducing heterogeneous agents into this framework we show that the virtuous circle of pecuniary externalities making a region attractive are not the same for all individuals. The bell-shaped curve of spatial development found by NEG with agglomeration in the first step of trade integration followed by dispersion in the second step, masks a sorting of individuals and firms. Activities that remain in the core during the process of dispersion are not the same in terms of productivities and skills than those that flee to the periphery and this sorting can spatially influence the opportunity costs of skill upgrading by unskilled workers.

Formally, we extend Okubo's model (2010), in which heterogeneous individuals create firms that evolve in two directions under increasing returns and monopolistic competition. Firstly we introduce housing, an important good explaining sorting since the price of land plays a major role in influencing the cost of living and location choices (Helpman, 1998; Murata and Thisse,

\footnotetext{
${ }^{1}$ Glaeser (2005 a,b) provides vivid pictures of the role of natural advantages in the economic history of NewYork and Boston. See also Glaeser and Kohlhase (2004) who analyzes how the trade costs have decreased over the twentieth century (by over $90 \%$ in real terms) making geographical advantage in production increasingly irrelevant to explain the spatial economy.

${ }^{2}$ See Helsley and Strange, 1990; Venables, 2011.

${ }^{3}$ Port facilities are obviously the first large indivisibilities that fostered agglomeration economies explaining the density of populations but many other facilities mattered such as those presented by Burchfield, Overman, Puga, and Turner (2006) who find that residences are closer to each other in cities where the water supply relies on shared public facilities.

${ }^{4}$ See Combes and Gobillon (2015) for the empirics of these agglomeration economies.

${ }^{5}$ See Fujita, Krugman and Venables (1999) for the general presentation and Mori and Turrini (2005) and Ottaviano (2012) for models in this field with heterogeneous individuals.
} 
2005; Pflüger and Südekum, 2008). ${ }^{6}$ The introduction of housing provides a new result in terms of spatial sorting: when trade costs are low, agglomeration is the optimal choice for high-skilled workers, while those with lower skills increasingly choose to leave the expensive city. Secondly, we introduce the modeling of education proposed by Redding and Schott (2004), to analyse how the migration of high skilled and low skilled workers influences investment in education/training by unskilled workers. ${ }^{7}$ We find that with full agglomeration, education investments decline at the periphery and increase in the core. However, with lower trade costs, a spatial convergence occurs in the share of entrepreneurs newly skilled in the periphery. Opportunities for local entrepreneurs increase in regional trade integration at a low level of trade costs.

A vast literature has emerged on the spatial sorting of individuals. ${ }^{8}$ Our main contribution is to consider the impact of regional trade costs on this sorting. These costs matter because they explain why a vast majority of goods are only traded locally. For instance in the U.S., Duranton, Morrow and Turner (2014) observe that internal trade accounts for about $70 \%$ of the weight of all trade in their sample of the Commodity Flow Surveys (CFS) in 2007. ${ }^{9}$ It has also been shown that internal trade costs, even in developed countries such as the U.S., has the potential to influence productivities (see Behrens, Mion, Murata, Südekum, 2013) and the diffusion of macroeconomic shocks (see Caliendo, Parro, Rossi-Hansberg et Sarte, 2014).

However, at the intersection of regional trade integration and spatial sorting, the literature is quite limited. A notable exception is Michaels (2008) who shows that the United States Interstate Highway System has led high-skilled workers to locate in skill-abundant counties. This empirical result is based on a model with factor endowments (i.e. the Heckscher-Ohlin model), we propose an alternative explanation based on agglomerations economies and market access. Moreover, we provide two extensions to Michaels's empirical analysis (2008). First, we work with a period preceding that studied by the author; this is the post-war period of 19401960 which to our knowledge has never been used to analyse the impact of the road revolution on the spatial distribution of skills. Secondly, we use the CFS to analyse in the contemporary period (1997-2007) whether regional integration ${ }^{10}$ still affects this distribution.

\footnotetext{
${ }^{6}$ Wrede (2014) also proposes a model with housing and skills heterogeneity but in a model with monopolistic competition for intermediate goods. He finds that the core will be larger than the periphery in terms of aggregate skills, population, and production.

${ }^{7}$ Redding and Schott (2004) show that by hindering market access, distance reduces job opportunities for skilled workers and funds invested in education.

${ }^{8}$ We survey this literature in the first part of this article.

${ }^{9}$ To explain this, one can evoke what Head and Mayer (2013) called the "dark matter" of the trade gravity which are: familiarity (information decaying with distance), localized tastes, and distribution networks. It is indeed costly to learn about market conditions elsewhere (Allen, 2014), which gives the regional market size a crucial role reducing information frictions. As shown by Chaney (2014) the fact that firms use their existing network of contacts to search remotely for new partners can explain why trade decrease so strongly with distance.

${ }^{10}$ We are especially concerned by the role of regional trade costs, consequently we work on a complete database of trade, including regional, interregional and international flows which allows us to build a multidimensional
} 
In the next section, we present the literature and our motivation in more details. The model is presented in the next section before outlining the theoretical results. A discussion of our findings is provided and the last section is devoted to an empirical analysis which aims at deepening this investigation by working on the United-States.

\section{The model}

\subsection{A brief survey of spatial sorting}

Our model is motivated by the empirical literature on location choices of individuals with heterogeneous skills. This literature analyzes what are the different location choices of highskilled, intermediate-skilled (often called low-skilled), and unskilled workers.

Behrens, Duranton and Robert-Nicoud (2014) show how highly productive workers are disproportionately represented in large cities because of tougher selection and agglomeration economies. Working on U.S. data from 1940 to 2010, Ganong and Shoag (2012) confirm this result by finding that high-skilled workers now move to productive and expensive places. They also find that low-skilled workers move to areas with low housing costs. Eeckhout, Pinheiro and Schmidheiny (2014) obtain a systematic pattern of fat tails - at both the top and bottom - of the skills distribution of large cities in the United States. ${ }^{11}$ Large cities attract the high-skilled and provide pecuniary externalities to unskilled workers. This was also the conclusion of Moretti (2012) who considered in a quite provocative sentence that what matters "in today's economy, it is not necessarily what you do, or who you know - it is where you live". Cities with a high concentration of skilled workers pay high average salaries to non-skilled workers.

More focused on sorting, Diamond (2013) shows an increase in the geographic sorting of college graduates who are concentrated in high wage, high rent metropolitan areas. Combes et al. (2008) and Mion and Naticchioni (2009) find evidence of sorting of skilled workers into the densest cities in France and Italy. Combes et al. (2010) find that the effect of density on wages is reduced by a half when worker fixed effects are introduced into the estimation. They consider this result as evidence of sorting: workers in denser cities have greater unobserved skills. ${ }^{12}$ Combes et al. (2012) make an important contribution by showing that the Darwinian selection of firms is not the main determinant of productivity differences across french cities. Instead, agglomeration economies appear crucial in explaining the French spatial economy.

\footnotetext{
trade costs indicator, including an internal border component.

${ }^{11}$ See also Behrens and Robert-Nicoud (2014) who propose an elegant model with natural advantage, agglomeration economies, and selection explaining why large cities are both more productive and more unequal than small towns.

${ }^{12}$ See Baum-Snown and Feirrera (2015) for an extensive discussion on empirical methods to capture spatial sorting and other effects.
} 
These works reveal the importance of housing costs (Ganong and Shoag, 2012), agglomeration economies (Behrens et al. 2014, Combes et al. 2012) and education (Diamond, 2013) in explaining the spatial sorting. As a consequence, we integrate these elements into our framework. There are however two differences with this literature. Firstly as explained in the introduction, we focus on the impact of regional trade costs on the sorting of individuals. Secondly, we do not study how migration is motivated by investment in education (e.g. Diamond, 2013), but how the migration of skilled workers influence skills acquisition by the unskilled who become entrepreneurs. In other words, we analyse how endogenously determined market size can influence investment in education and the emergence of a local class of entrepreneurs. ${ }^{13}$ This idea proposed by Redding and Schott (2004) in a model of international trade, may deserve to be applied at the regional level within countries. In fact, we follow them when they write: "This paper provided the first evidence of a positive correlation between countries' human capital investment and measures of access to centers of world economic activity. [...] Potentially fruitful avenues for further inquiry include looking for a similar relationship across regions within countries".

\section{$2.2 \quad$ Preferences}

The economy contains three sectors and two regions. Each household's preference takes the Pflüger and Südekum (2008) form:

$$
\begin{aligned}
U_{r} & =\mu \ln M_{r}+\gamma \ln H_{r}+A \\
\text { where } \quad M_{r} & =\left[\int_{i \in n_{r}} m_{r r}(i)^{\frac{\sigma-1}{\sigma}} d i+\int_{i \in n_{s}} m_{r s}(i)^{\frac{\sigma-1}{\sigma}} d i\right]^{\frac{\sigma}{\sigma-1}} \\
\text { with } r, s & =1,2 \text { and } r \neq s
\end{aligned}
$$

such that $M_{r}$ is the consumption of an industrial composite, $n_{r}$ is a set of varieties produced in region $r(r, s=1,2)$ and $\sigma>1$ is the elasticity of substitution among these varieties. Furthermore, $A$ is the consumption of the homogeneous good produced under constant returns to scale using unskilled workers; $H_{r}$ refers to the consumption of housing; $\mu$ and $\gamma$ represent preference parameters. ${ }^{14}$

Varieties are exchanged between regions with trade costs, which take the form of iceberg

\footnotetext{
${ }^{13}$ Glaeser, Ponzetto and Tobio (2014) do not study regional trade costs. However as in the current model, they consider that education increases the level of entrepreneurship.

${ }^{14}$ We introduce a standard restriction with quasi-linear utility regarding income that must be high enough to ensure consumption of all goods: $\gamma+\mu<Y$ (see Bardes and Peirson, 2010; Dixit, 1990).
} 
costs: $\tau_{r s}>1$ units of a variety must be sent from $r$ for one unit that arrives in $s$. Symmetrical costs are assumed, $\tau_{r s}=\tau_{s r}=\tau$, and internal costs are not considered, $\tau_{r r}=1$.

The solution to the utility maximization problem generates the following demands in $r$ for a typical variety produced in location $r$ and $s$ :

$$
\begin{aligned}
& m_{r r}(i)=\mu p_{r}(i)^{-\sigma} P_{r}^{\sigma-1} \\
& m_{r s}(i)=\mu\left[\tau_{r s} p_{s}(i)\right]^{-\sigma} P_{r}^{\sigma-1}
\end{aligned}
$$

with $P_{r}$ the price index in $r$, equal to:

$$
P_{r}=\left[\int_{i \in n_{r}} p_{r}(i)^{1-\sigma} d i+\int_{i \in n_{s}} p_{s}(i)^{1-\sigma} \phi d i\right]^{\frac{1}{1-\sigma}}
$$

where $\phi$ is a measure of trade openness, such that $\phi=\tau_{r s}^{1-\sigma}$. The aggregated demand for housing is given by:

$$
H_{r}=\gamma\left(L_{r, h}^{S}+L_{r, l}^{S}+L_{r}^{U}\right) / p_{r}^{H}
$$

where $p_{r}^{H}$ is the price of housing, and $L_{r, h}^{S}, L_{r, l}^{S}$ and $L_{r}^{U}$ represent populations of high skilled, low skilled and unskilled workers, respectively. Unskilled workers earn a wage $w_{r}^{U}$ in the region $r$ and skilled workers earn $w_{r h}^{S}$ in a firm with high fixed costs or $w_{r l}^{S}$ in a firm with lower fixed costs. Firms and workers move hand-in-hand, which means that workers' migration drives firm's mobility. This leads to the merging of entrepreneurs and skilled workers. ${ }^{15}$ Lastly, as described below, firm's technologies may differ in the industrial sector.

\subsection{Technologies}

In the homogeneous good sector, perfect competition ensures that a traditional good is priced at its marginal cost. This good is chosen as the numeraire, and since it is costlessly traded, the nominal wage rate is unity in countries 1 and 2 . In the housing sector, supply is exogenously given by a regional stock $H_{r}$.

In the industrial composite sector, as in Okubo (2010), firms are heterogeneous regarding the fixed cost of production, denoted $f_{j}$. This fixed cost represents the requirement for skilled labor to launch a new variety ${ }^{16}$. Firms created by low skilled workers have higher fixed costs

\footnotetext{
${ }^{15}$ The two terms are equivalently used in prior literature. Krugman (1991) and Robert-Nicoud (2005) speak of regional migration of workers. Instead Baldwin et al. (2003) present mobile individuals as footloose entrepreneurs, whereas Forslid and Ottaviano (2003) speak about skilled workers. However, when turning towards the empirical analysis the model is more often used to analyse migration of workers than relocation of entrepreneurs (Glaeser et al., 2010). See for instance Bosker et al. (2012) who analyse regional migration in China.

${ }^{16}$ See also Forslid and Ottaviano (2003).
} 
$f_{h}$ than firms with high skilled workers who bear a lower fixed cost $f_{l} .{ }^{17}$ The variable cost $\beta$ is identical for all firms. The total cost of producing $q_{r, j}$ units of a typical manufactured variety in region $r$ is:

$$
T C_{r, j}=f_{j} w_{r, j}^{S}+\beta w_{r}^{U} q_{r, j} \quad j=h, l .
$$

According to the Dixit-Stiglitz monopolistic competition in sector M, a typical firm sets the following price:

$$
p_{r}=\beta \sigma /(\sigma-1) \text {. }
$$

A firm's operating profits are entirely absorbed by its wage bill, so that with Equations (4) and (5), the level of output is given by:

$$
q_{r, j}=(\sigma-1) \frac{f_{j}}{\beta} w_{r, j}^{S}
$$

At the equilibrium, a firm employs $f_{j}$ units of skilled workers and there are $n_{r, j}$ firms. Thus the demand for each kind of skilled labor is given by $f_{j} n_{r, j}$. Supply depends on the heterogeneity of skilled workers, which is exogenously given. There are $L_{r, j}^{S}$ skilled workers of kind $j=l, h$. Therefore, the number of firms created is:

$$
n_{r, j}=\frac{L_{r, j}^{S}}{f_{j}},
$$

which decreases with both different fixed costs of production.

\subsection{Market clearing}

Market clearing for a domestic variety $i$ is expressed by $y_{r}(i)=L_{r} m_{r r}(i)+L_{s} \tau m_{r s}(i)$. Inserting demands' functions, referred to Equations (1) and (2), and using supply from Equation (6), we derive the following equilibrium wages:

$$
\begin{aligned}
w_{1, h}^{S} & =\frac{\beta^{1-\sigma} \mu}{\sigma^{\sigma}(\sigma-1)^{1-\sigma} f_{h}}\left[\frac{L_{1}}{P_{1}^{1-\sigma}}+\frac{L_{2}}{P_{2}^{1-\sigma}} \phi\right], \text { and } \\
w_{1, l}^{S} & =\frac{\beta^{1-\sigma} \mu}{\sigma^{\sigma}(\sigma-1)^{1-\sigma} f_{l}}\left[\frac{L_{1}}{P_{1}^{1-\sigma}}+\frac{L_{2}}{P_{2}^{1-\sigma}} \phi\right],
\end{aligned}
$$

\footnotetext{
${ }^{17}$ This perfect matching between skilled workers and productive firms may be related to Mion and Naticchioni's (2009) finding on the Italian market: "good" workers match up with "good" firms. Irarrazabal, Moxnes and Ulltveit-Moe (2013) also find that part of the difference between high and low productive firms comes from assortive matching. A critical point of this assumption is however that it is more likely that firms hiring highskilled workers will exhibit more economies of scale than firms with low skilled workers. However, because wages are the residual claimant of profit this is unsuitable with our objective to consider high-skilled workers who earn more than low-skilled, i.e. $w_{r h}^{S}<w_{r l}^{S}$. In short, the assumption of $f_{h}>f_{l}$ is done to ensure that $w_{r h}^{S}<w_{r l}^{S}$.
} 
where $\phi=\tau^{1-\sigma}$, denotes a measure of trade openness, and $P_{1}$ and $P_{2}$, the price indices, obtained by inserting the optimal price from Equation (5) and the optimal number of firms from Equation (7) in the price index

$$
\begin{aligned}
\frac{P_{1}^{1-\sigma}}{\left(\frac{\sigma}{\sigma-1}\right)^{1-\sigma}}= & \frac{L_{1, h}^{S}}{f_{h}} \beta^{1-\sigma}+\phi \frac{L_{2, h}^{S}}{f_{h}} \beta^{1-\sigma} \\
& +\frac{L_{1, l}^{S}}{f_{l}} \beta^{1-\sigma}+\phi \frac{L_{2, l}^{S}}{f_{l}} \beta^{1-\sigma}
\end{aligned}
$$

Different forces drive these nominal wages. On the one hand, an increase of the number of workers in a region exacerbates local competition, so as $\phi$ increases, a new entry triggers a slump in the price index (as long as $\phi<1$ ), and thereby in operating profits, so that in order to stay in the market, the residual profits that ends in the entrepreneurs wage decrease. This is the market crowding effect where relocation impacts on price indices (9) and then on wages (8). But, on the other hand, more skilled workers/consumers imply more outlets for firms, so sales and operating profits increase, and under the zero profit condition, this affects the nominal wage. This is the market access effect, where migration impacts on the numerator of Equation (8). Concerning firms' heterogeneity, the wage equation indicates that the market access effect is higher for firms with a lower fixed cost. On the opposite side, the market crowding effect increases with low fixed costs.

On the housing market, as in Pflüger and Südekum (2008), the equilibrium between demand and supply gives the following price of housing:

$$
p_{r}^{H}=\gamma L_{r} / H,
$$

where $L_{r}$ denotes total population in region $r$. This may be viewed as an expression of congestion costs when workers arrive in a region. The total population depends on the number of workers of $\mathrm{h}$ and l-types, as well as the population of immobile workers:

$$
L_{r}=L_{r, h}^{S}+L_{r, l}^{S}+L_{r}^{U}
$$

\subsection{Location choice}

Skilled workers are mobile between regions according to indirect utilities $V_{r}^{S}$ :

$$
V_{r, j}^{S}=w_{r, j}^{S}-\mu \ln P_{r}-\gamma \ln p_{r}^{H}+c
$$


which then depend on nominal rewards and prices with $c \equiv \mu \ln (\mu-1)+\gamma \ln (\gamma-1)$.

Skilled workers respond to existing differences in welfare. Migration stops when real wages are equalized in the case of symmetry, or when agglomeration in one region generates a higher real wage than that prevailing in the other region. The crucial variable is then $\Omega$, defined as the indirect utilities' differential, expressed by:

$$
\begin{aligned}
\Omega_{j} & =V_{1, j}^{S}-V_{2, j}^{S} \\
& =w_{1, j}^{S}-w_{2, j}^{S}+\mu \ln \left(P_{2} / P_{1}\right)+\gamma \ln \left(p_{2}^{H} / p_{1}^{H}\right) .
\end{aligned}
$$

This location choice equation introduces an agglomerative and a dispersive force linked to consumption (in addition to forces linked to wages and presented previously). Goods are cheaper in the agglomerated area because imports are lower, therefore the burden of trade costs decreases too. In contrast, agglomeration increases the price of land and fosters dispersion. This latter force does not depend on trade costs, so while all other effects fade with trade liberalization, the price of land determines the location choices for low trade costs.

The conditions in which the symmetric interior equilibrium is stable are given when any deviation leads to a decrease of the relative indirect utility. In the next section we analyse both break points of dispersion and sustain points of agglomeration.

\section{$3 \quad$ Spatial sorting}

\subsection{Stability of dispersion}

Because we work with regions that initially had identical technology and endowments of immobile factors, a symmetric equilibrium exists; this however can be unstable. When dispersion becomes unstable for one type of worker, the departure of these workers destabilizes the dispersive equilibrium of the other group. To obtain the range of trade costs for which dispersion is stable, we determine for whom dispersion is first broken, by comparing the break point of each kind of worker. Thus we resolve $\partial \Omega_{h} /\left.\partial L_{h}^{S}\right|_{L_{l}^{S}=L_{h}^{S}=0.5}=0$ and $\partial \Omega_{l} /\left.\partial L_{l}^{S}\right|_{L_{h}^{S}=L_{l}^{S}=0.5}=0$, which give various solutions (denoted $\underline{\phi_{h}^{B}}, \overline{\phi_{h}^{B}}$ and $\underline{\phi_{l}^{B}}, \overline{\phi_{l}^{B}}$ ), only two of which are bifurcation points, called "break points". ${ }^{18}$

Okubo (2010) has already discovered one break point for high trade costs. The intuition is that for high trade costs, the competition effect is strong, leading high-skilled entrepreneurs to flee agglomeration. In contrast, for low productive firms competition in the core is relatively weaker making agglomeration sustainable. Trade integration by reducing the dispersive force

\footnotetext{
${ }^{18}$ We relegate the expression of these break points and proof to Appendix A (Equations 18 and 19).
} 
of competition, leads to an agglomeration of high skilled workers. This corresponds to Okubo's Proposition 1 (2010).

By introducing housing, we find a second break point for low trade costs. This is not a surprising result, the price of land is a centrifugal force that makes dispersion stable for low trade costs. Krugman and Livas-Elizondo (1996), Helpman (1998), Murata and Thisse (2005), Pflüger and Südekum (2008) and Candau (2011) have already demonstrated such a result in different models and consequently we consider it as a "Folk Theorem" of NEG. This result has found much empirical support. For instance Combes, Lafourcade, Thisse and Toutain (2011) show that French activities have been more dispersed since the middle of the past century. Brülhart and Traeger (2005) underscore a similar process for European nations and BaumSnow, Brandt, Henderson, Turner, and Zhang (2011) find a positive effect of railroads in the Chinese decentralization of manufacturing production.

We upgrade the Folk Theorem by introducing heterogeneous workers which makes it possible to analyse sorting. We find the following result.

Proposition 1 When trade is liberalized, the stability of dispersion for low trade costs depends on high skilled-workers (low-skilled jobs follow high-skilled jobs): dispersion is stable for $\left[\overline{\phi^{B}}=\right.$ $\left.\overline{\phi_{l}^{B}}, 1\right]$.

Proof. See Appendix B.

The intuition behind this result is that when trade costs are small enough, the advantage of being where the demand is agglomerated decreases, even though the drawback of the high price of land remains for both categories of workers. Therefore, when skilled workers choose dispersion, demand is better spatially balanced, and low-skilled workers find job opportunities at the periphery. Thus low-skilled workers follow high-skilled workers, and dispersion is again stable. The reverse is not true, i.e the dispersion of low-skilled does not lead to the dispersion of high-skilled, because the agglomeration rent of productive firms is higher and so, even in the case of a partial dispersion of low-skilled workers, it remains profitable for high skilled entrepreneurs to stay in the core. This latter case is analysed in more detail in Subsection 3.3 showing wages and price index under the different equilibria.

\subsection{Core-periphery equilibrium}

Another natural equilibrium is the core-periphery equilibrium. To characterize the stability of this equilibrium, we can evaluate relative real wages when all workers are located in Region 1. This equilibrium is stable if agglomeration provides higher welfare than that obtained in periph- 
eral Region 2. Sustain points refer to the critical values of trade costs at which agglomeration is sustainable.

For high trade costs (i.e., $\phi<\underline{\phi_{l}^{B}}$ ); (see the Appendix for expressions and proof), agglomeration in one region is the sole equilibrium for low-skilled workers, though a partial dispersion of high-skilled workers is still possible. When trade costs decrease $\left(\phi \in\left[\phi_{l}^{S}, \overline{\phi_{h}^{S}}\right]\right)$, overall agglomeration of low skilled and high skilled workers occurs in Region 1. Okubo (2010) shows that this result holds until free trade. By introducing housing we show that this result can be stable only for intermediate value of trade costs. When trade costs decrease even more $\left(\phi>\overline{\phi_{h}^{S}}\right)$, a partial dispersion of low skilled workers occurs, such that they are the first to flee intense competition and high land prices in the core. Perhaps even more interesting, the agglomeration of high skilled workers in the core is a stable equilibrium, despite the dispersion of demand due to migration by low skilled workers. The elasticity of the regional wage gap is higher for highskilled than for low-skilled workers, implying that agglomeration which widens this gap is more profitable for high-skilled workers. In short, high-skilled workers benefit from the agglomeration rent. We retain:

Proposition 2 For deep trade integration there is dispersion of low-skilled workers and agglomeration of high-skilled workers.

Proof. See Appendix C.

These results echo the findings of Ganong and Shoag (2012) for the U.S. who write:

"Low-skilled workers are especially sensitive to changes in housing prices. We show that in recent years (1) the real returns to migration to productive places have fallen dramatically for low-skilled workers but have remained high for highskilled workers, (2) high-skilled workers continue to move to areas with high nominal income, and (3) low-skilled workers are now moving to areas with low nominal income but high real income net of housing costs."

In the next two subsections, we present numerical simulations showing and explaining how our model predicts relocation of low-skilled workers from the core to the periphery.

\subsection{Bifurcation diagram}

Figure 1 illustrates results the of Propositions 1 and 2 by plotting location choices with respect to trade costs (the last plot in Figure 1). To evaluate the stability of location, we have to 
systematically analyse the choice of both types of workers under various configurations (the two plots at the top). We successively study the stability of the following distribution of talents: ${ }^{19}$

1. Agglomeration of low-skilled workers when there is total agglomeration of high-skilled workers and vice-versa. In short we resolve $\left.\Omega_{h}\right|_{L_{l}^{S}=L_{h}^{S}=1}=0$ and $\left.\Omega_{l}\right|_{L_{l}^{S}=L_{h}^{S}=1}=0$ for $\gamma$.

2. Dispersion of high-skilled workers when low-skilled workers are dispersed (and vice versa). Resolving $\partial \Omega_{h} /\left.\partial L_{h}^{S}\right|_{L_{l}^{S}=L_{h}^{S}=0.5}=0$ and $\partial \Omega_{l} /\left.\partial L_{l}^{S}\right|_{L_{h}^{S}=L_{l}^{S}=0.5}=0$ according to $\gamma$.

3. Agglomeration of low-skilled workers when there is partial dispersion of high-skilled workers (we arbitrarily analyse the stability of $\left.L_{l}^{S}=0.2\right)^{20}$ and vice-versa. We resolve $\left.\Omega_{h}\right|_{L_{h}^{S}=1, L_{l}^{S}=0.2}=0$ and $\left.\Omega_{l}\right|_{L_{l}^{S}=1, L_{h}^{S}=0.2}=0$ for $\gamma$.

4. Partial dispersion of low skilled (we arbitrary analyze the stability of $L_{h}^{S}=0.2$ ) when there is a total agglomeration of high-skilled and vice-versa, i.e. this leads to resolve $\left.\Omega_{h}\right|_{L_{h}^{S}=0.2, L_{l}^{S}=1}=0$ and $\left.\Omega_{l}\right|_{L_{l}^{S}=0.2, L_{h}^{S}=1}=0$.

The panel at the top represents the situation of low-skilled workers while the panel in the middle displays that of high-skilled workers. These two graphics make it possible to analyse various bifurcation diagrams called tomahawk diagrams in NEG jargon. Indeed for a given level of $\gamma$ we can observe location choice for all values of trade costs. For instance by drawing an horizontal line for $\gamma=0.04$ we obtain the location choice at the equilibrium presented at the bottom of Figure $1 .^{21}$

Perfect dispersion is possible for high trade costs. Indeed at $\gamma=0.04$ we have a range of trade freeness for which $\phi<\underline{\phi_{h}^{B}}$. Partial dispersion of the high-skilled and full agglomeration of the low-skilled is also an equilibrium due to the strong dispersive force of competition for high-skilled workers. In the Appendix we report (for the same value of parameters) the real wages differential allowing observing the partial dispersion of the high-skilled which contrasts with the agglomeration of low-skilled workers.

Then, trade integration leads to the agglomeration of each kind of worker. However, lowskilled workers start gradually to flee the core. When trade costs are sufficiently low, both high skilled and low skilled workers can be dispersed. Thus from a situation that may be called a "melting-pot", in which regions have identical skill composition, a significant shock can induce spatial sorting and segregation with low-skilled workers at the periphery and high skilled workers in the core.

\footnotetext{
${ }^{19}$ Parameters: $\sigma=4, \beta=1, L_{i m}=2, \mu=0.2, f_{l}=1.5, f_{h}=2$.

${ }^{20}$ This number $\left(L_{l}^{S}=0.2\right)$ is chosen simply to obtain a nice graphic.

${ }^{21}$ The reader can thus draw other bifurcation diagrams by setting another value of $\gamma$.
} 
This spatial pattern appears to be very robust. For instance in the Appendix we double the fixed costs of less productive firms and obtain similar results. The main difference concerns the case of perfect dispersion which is broken by heterogeneity for a wide range of trade costs. Agglomeration is more likely to take place in regions with strong heterogeneity.

Figure 1: Location choices with respect to trade costs

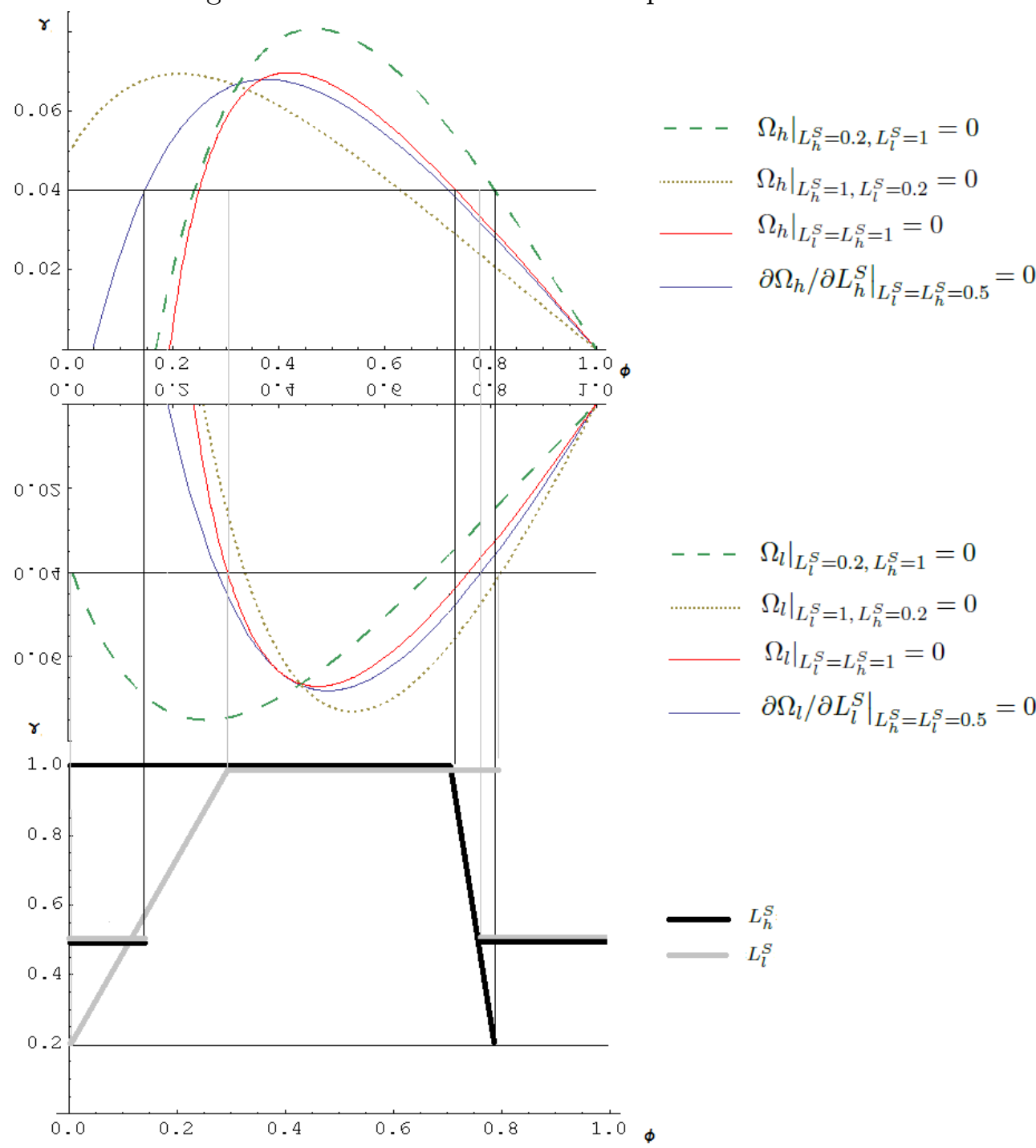

Lastly regarding the top of Figure (1) it can be seen that these numerical simulations allow scanning different cases (i.e. tomahawk diagrams). For instance at $\gamma=0$ the Okubo's result (2010) can be observed in which spatial sorting and dispersion do not occur when trade costs are low (the upper break point and sustain point are obtained at $\phi=1$ ). One can also draw location choices at the equilibrium when preference for housing is higher (e.g. $\gamma=0.06$ ). In that case, the range of trade costs, for which agglomeration is sustainable, decreases. Finally, it is even possible to plot the bifurcation diagram by setting a value of trade costs and to change the housing parameter $\gamma$. For instance by setting $\phi=0.6$ it can be observed that an 
increase of $\gamma$ from zero, leads from a situation in which both sets of workers are agglomerated to a situation in which the low-skilled choose relocation to the periphery while the high-skilled remain agglomerated. For a high value of $\gamma$, perfect dispersion is also stable.

\subsection{Forces at work}

The previous analysis is relatively general enabling the analysis of location for a constellation of trade and urban costs. However it has the drawback of masking effects at work since nominal wages and price indices are not represented. We thus propose a complementary analysis to better illustrate our results. In Figure (2) we report real wage differential for high-skilled and low-skilled workers, $\Omega_{l}$ and $\Omega_{h}$ as a function of $L_{l}^{S}$ and $L_{h}^{S}$ for various levels of trade costs using the same set of parameters as in the previous analysis (Figure, 1$).{ }^{22}$ This real wage differential is represented by a thick line. When this differential is positive there is agglomeration in region 1 and when the slope of this differential with respect to migration is negative and cuts the horizontal line, there is dispersion. We speak about perfect dispersion when workers are equally distributed between regions, and about partial dispersion in the case of unequal distribution. We also decompose the indirect utility of each type of worker to better understand what happens. The nominal wage differential, which encapsulates competition and market access effects, is represented by a regular line. The relative price index in region 2 , which is driven by the costs of living effect (which also gives precious information regarding the competition effect because these two effects come from the price index) is represented by a dashed line. Lastly the relative price of housing in region 2 is represented by a dotted line.

$$
\underbrace{\Omega_{j}}_{\text {Thick line }}=\underbrace{w_{1, j}^{S}-w_{2, j}^{S}}_{\text {Regular line }}+\underbrace{\mu \ln \left(P_{2} / P_{1}\right)}_{\text {Dashed line }}+\underbrace{\gamma \ln \left(p_{2}^{H} / p_{1}^{H}\right)}_{\text {Dotted line }}
$$

In Figure (2.1) we plot wages and prices for high-skilled workers by assuming full agglomeration of the low-skilled. The thick line shows a stable partial dispersion of high-skilled workers (20\% are located in region 1) under this assumption of full agglomeration of low-skilled workers. In Figure (2.2) we verified that with $20 \%$ of high-skilled workers in region 1, a full agglomeration of the low-skilled in this region is an equilibrium. Effects at work are quite similar for the two types of workers. For low-skilled workers, the process of agglomeration leads to higher housing prices (which dominate the lower price of industrial goods produced there) and to higher nominal wages. But the most interesting result concerns the elasticity of the regional wage gap with respect to agglomeration, which is smaller for low-skilled workers, implying that agglomeration

\footnotetext{
${ }^{22}$ Parameters: $\gamma=0.04, \sigma=4, \beta=1, L_{i m}=2, \mu=0.2, f_{l}=1.5, f_{h}=2$.
} 
leads to a smaller decrease of wage for this group. In other words, because high-skilled workers are more productive, the competition effect is stronger and represents a push factor for these individuals explaining their dispersion.

Figure 2: Partial agglomeration of high-skilled and agglomeration of low-skilled workers

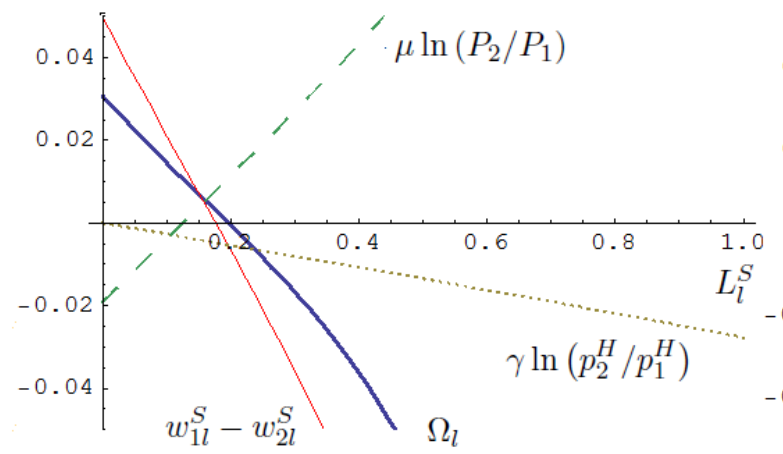

1. High-skilled with $\phi=0$ and $L_{h}^{S}=1$

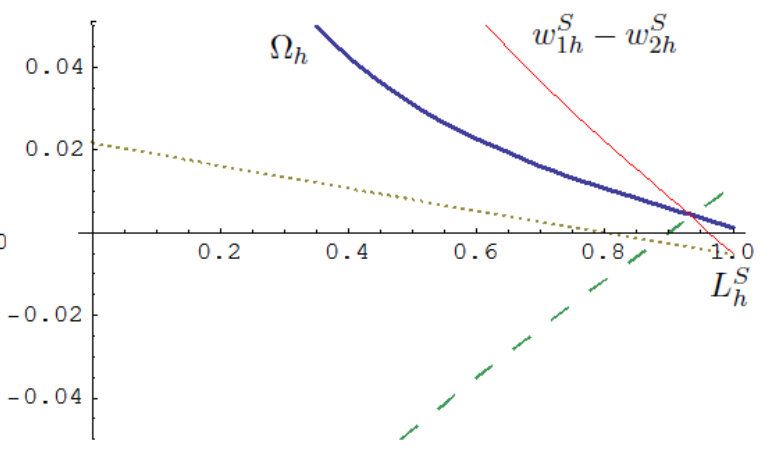

2. Low-skilled with $\phi=0$ and $L_{l}^{S}=0.2$

If we now destabilize this equilibrium, by considering that high-skilled workers migrate to the core (or by considering that low-skilled workers go to the periphery), then a situation of perfect dispersion for both types of workers is a stable equilibrium. This is represented in Figure (3) in which (for the same value of parameters as previously) we set the dispersion of one type of workers and we verify the dispersion of the other type.

Figure 3: Equal distribution of talents

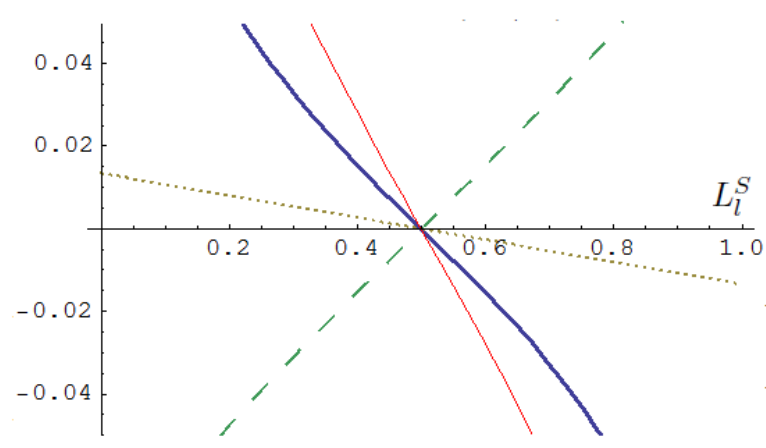

1. High-skilled with $\phi=0$ and $L_{h}^{S}=0.5$

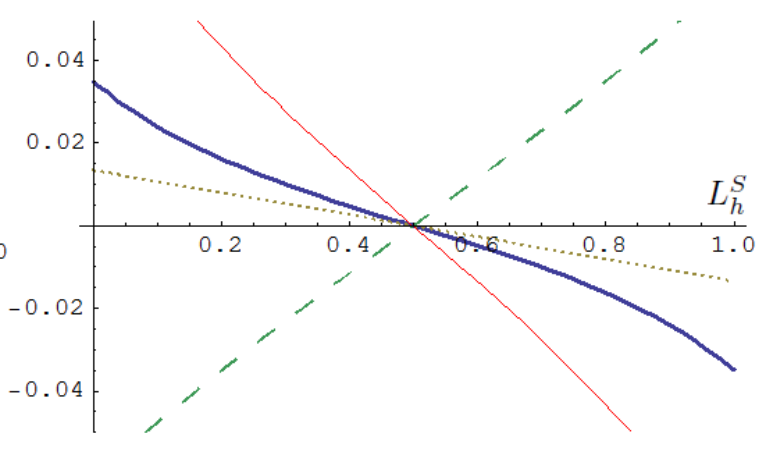

2. Low-skilled with $\phi=0$ and $L_{l}^{S}=0.5$

For a lower value of trade costs, total agglomeration in region 1 is stable for both highskilled and low-skilled workers as illustrated in Figure (4). There are no striking differences with previous graphics regarding wages and prices (dashed, dotted and regular line), indeed both dispersive and agglomeration forces decrease in magnitude with trade liberalization (see Baldwin, Forslid, Martin, Ottaviano and Robert-Nicoud 2004). Agglomeration is stable because this new spatial configuration implies a strong decrease in the relative price of industrial goods 
and only a small decrease in relative wages and a weak increase in housing price.

Figure 4: Full agglomeration

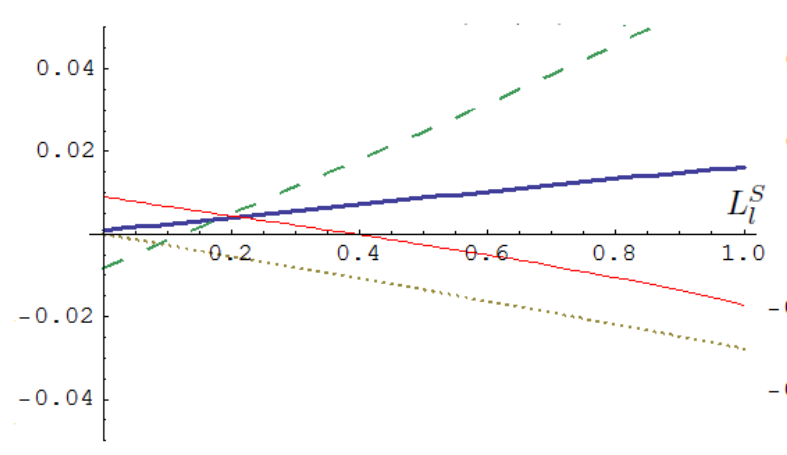

1. High-skilled with $\phi=0.4$ and $L_{h}^{S}=1$

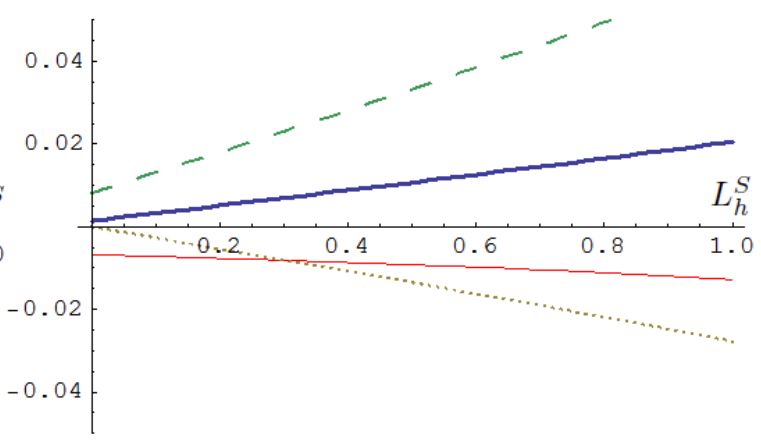

2. Low-skilled with $\phi=0.4$ and $L_{l}^{S}=1$

This seems counter-factual for it is often considered that relative nominal wages increase with population growth. However, such a result is temporary: for deeper trade integration, the relative wage increases with agglomeration. This is illustrated in Figure (5.1 and 5.2). In this case, agglomeration in region 1 is still an equilibrium for high-skilled workers while lowskilled workers are partially dispersed. This spatial sorting is once again due to the elasticity of the nominal wage with the entry of new workers (competition effect). As previously the wage elasticity of the low-skilled is lesser, but now the relative wage is increasing which means that agglomeration is less profitable for low-skilled than for high-skilled workers. High-skilled workers earn an agglomeration rent that allows them to pay for expensive housing.

Figure 5: Agglomeration of high-skilled and partial dispersion of low-skilled workers

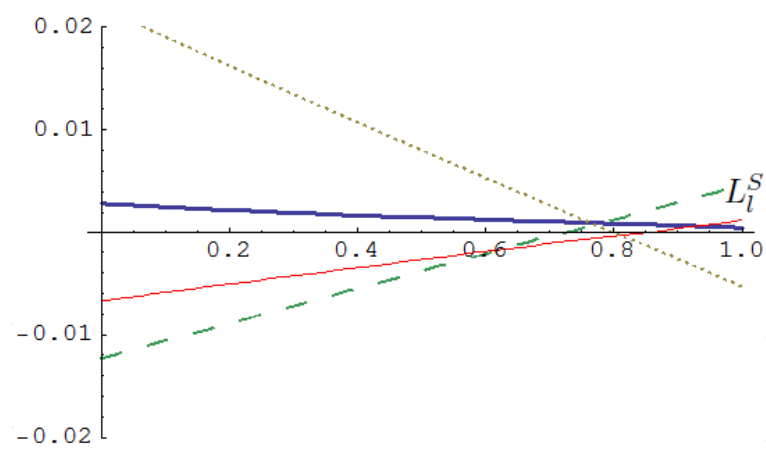

1. High-skilled with $\phi=0.81$ and $L_{h}^{S}=0.2$

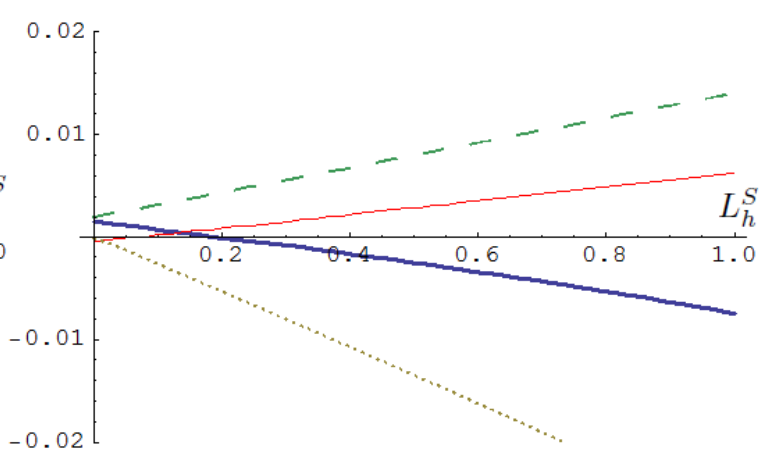

2. Low-skilled with $\phi=0.81$ and $L_{l}^{S}=1$

Lastly, for the same set of parameters, dispersion of both types of workers is an equilibrium as Figure (6) shows. 
Figure 6: Dispersion

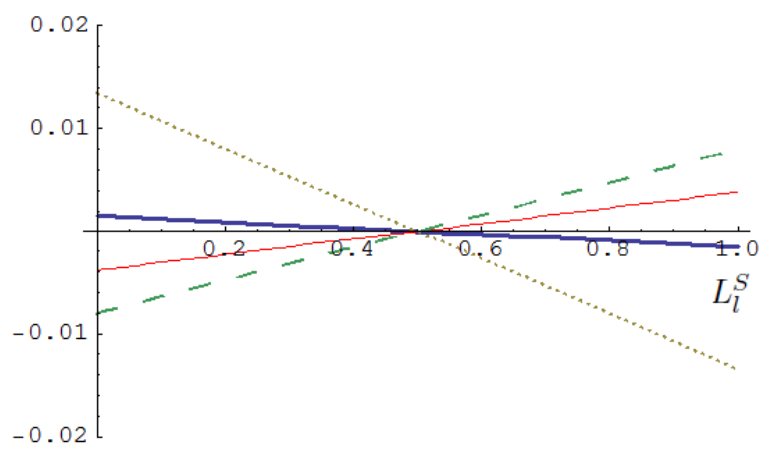

1. High-skilled with $\phi=0.81$ and $L_{h}^{S}=0.5$

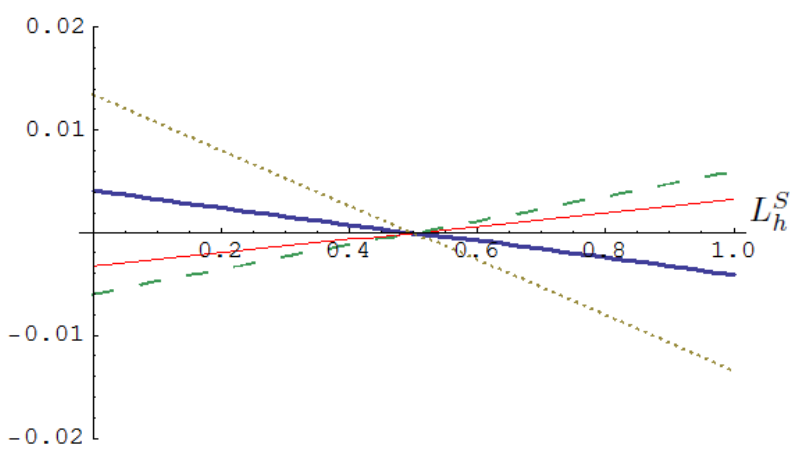

2. Low-skilled with $\phi=0.81$ and $L_{l}^{S}=0.5$

\subsection{Discussion}

To conclude, the main results of this section concern spatial sorting with the most productive agents remaining agglomerated in the core for a deep level of trade integration. Empirically, this result matches the fact that larger cities host more talented individuals (e.g., Combes, Duranton, Gobillon and Roux, 2012; Diamond, 2013). One can also find support for this result in Michaels (2008) for the U.S. and in Ghani, Goswami, and Kerr (2012) who show that improvement in India's highways had a positive impact on the sorting of productive plants.

Lastly, concerning economic history, Cronon (1992) documents how St. Louis has been overshadowed by Chicago thanks to rail networks. Even if spatial sorting is not addressed, complementary information is available. Sokoloff and Khan (1989) in particular underline that innovation was low-demanding in terms of skills and explain how the expansion of markets brings opportunities for simple/practical innovations. As a result, even low-skilled individuals were able to launch a new product. ${ }^{23}$

All this literature raises the question of "learning" in cities. According to Glaeser (1999), on the one hand big cities offer young workers interactions with experienced workers in order to acquire skills, On the other, experienced workers benefit from the rent afforded by this learning process. De La Roca, Ottaviano and Puga (2014) provide an overlapping generations model of urban sorting in which this virtuous mechanism can be broken by young individuals' imperfect assessment of their ability. They write:

"A partial explanation for little sorting on ability is simply that many people are not mobile. In the United States, $56 \%$ of people live at age 40 in the same city or town where they were at age 14 . [...] one would expect them to take into account

\footnotetext{
${ }^{23}$ By showing that this period was characterized by a relatively elastic supply of inventions, Sokoloff and Khan (1989) conclude that the expansion of markets had allowed a spread of inventive activity. They also document major shifts in the occupational and geographic distributions of patents.
} 
how they would fare in different cities depending on their ability. Our starting point in this paper is that it is not all that easy for individuals to make such a calculation."

De La Roca, Ottaviano and Puga (2014)

This justifies our next section in which we introduce the fact that many entrepreneurs are not mobile but can be spurred on to enter their local market by the example of the happy few who are footloose.

\section{Education}

We extend the footloose heterogeneous entrepreneurs model by considering that unskilled workers can become entrepreneurs via investment in education. This extension follows Redding and Schott (2004). ${ }^{24}$

We assume that unskilled workers are still immobile when becoming entrepreneurs. ${ }^{25}$ This may be justified by the fact that people who already work in a region as unskilled workers can have developed a home bias that ties them to the territory. ${ }^{26}$ Thus, beside high-skilled and low-skilled entrepreneurs (who behave exactly as in the previous section), a third category of entrepreneurs is considered: the population of immobile entrepreneurs, denoted $L_{r, i m}^{S}$, who earn $w_{r, i m}^{S}$ in region $r$.

Unskilled workers are heterogeneous regarding their ability $\alpha$ to learn how to become an entrepreneur. Unskilled workers are indexed by their abilities, uniformly distributed between $[0,1]$. The cost of education, denoted $\Gamma_{r}$, is exogenous. The real cost of learning differs across individuals according to their abilities $\alpha$. This cost is given by $\Gamma_{r} w_{r}^{U} / \alpha_{r}$ to capture the idea that high-ability individuals need fewer resources to invest in human capital. ${ }^{27}$ As Redding and Schott (2004, Footnote 3) have shown, an alternative model in which the cost of education is the same for all individuals but the rate of return varies with ability, is strictly equivalent. ${ }^{28}$ Workers invest in education if the wage differential between skilled and unskilled workers exceeds education costs $w_{r, i m}^{S}-w_{r}^{U} \geq \Gamma_{r} w_{r}^{U} / \alpha_{r}$. The resolution of this equation reveals a cutoff level

\footnotetext{
${ }^{24}$ See also Glaeser, Ponzetto and Tobio (2014) who propose a model in which education increases the level of entrepreneurship.

${ }^{25}$ For now we do not impose restrictions regarding their skills i.e. they are high-skilled if the fixed costs of the production of firms managed by these entrepreneurs is equal or smaller than that of firms launched by high skilled entrepreneurs $f_{i m}<f_{l}$, they are low skilled in the reverse case i.e. $f_{i m}>f_{h}$. In the numerical simulation we have considered that they are better skilled than the low-skilled but less skilled than the high skilled, $f_{h}>f_{i m}>f_{l}$.

${ }^{26}$ Thus, the systematic assumption in prior literature that "all entrepreneurs are mobile", is relaxed because it is not observed even in the United States where regional mobility is perhaps the highest among developed countries.

${ }^{27}$ The fact that education cost is proportional to wage is not neutral for the relationship between education effort and location equilibrium but we leave a more complex modeling for future research.

${ }^{28}$ See Falvey et al. (2010) for such a model.
} 
of ability, $\alpha_{r}^{*}$, that discriminates between workers who remain unskilled and those who acquire skills:

$$
\alpha_{r}^{*}=\frac{\Gamma_{r}}{w_{r, i m}^{S} / w_{r}^{U}-1} .
$$

This critical point is a reverse indicator of education, representing the number of unskilled workers. This cutoff depends on location for two reasons: 1) education costs can differ between regions ${ }^{29}$ 2) the relative wage can differ spatially; thus unskilled workers do not have the same opportunity cost to invest in education. In short the number of unskilled workers increases with respect to the relative wage $w_{r, i m}^{S} / w_{r}^{U}$ and education costs $\Gamma_{r}$. This result is Proposition 1 of Redding and Schott (2004).

Population, therefore, is divided into people with knowledge $\alpha_{r}\left(<\alpha_{r}^{*}\right)$ who have not invested in education and remain unskilled (denoted $L_{r}^{U}$ ), and people with knowledge $1-\alpha_{r}$ who learn and train to become entrepreneurs such that:

$$
\begin{aligned}
L_{r}^{U} & =\alpha_{r} L_{r, i m}, \text { and } \\
L_{r, i m}^{S} & =\left(1-\alpha_{r}\right) L_{r, i m},
\end{aligned}
$$

where $L_{r, i m}$ represents immobile/unskilled workers, and $L_{r, i m}^{S}$ is newly skilled entrepreneurs who are immobile.

Firms created by locals evolve under the same conditions as previous firms owned by high and low skilled entrepreneurs, but produce under different fixed costs, denoted $f_{i m}$. Demand for immobile skilled labor is given by $f_{i m} n_{r, i m}$ and supply by Equation (14), thus the number of immobile firms is:

$$
n_{r, i m}=\frac{\left(1-\alpha_{r}\right) L_{r, i m}}{f_{i m}} .
$$

From the zero profit condition, there is no profit in equilibrium and thus as for other entrepreneurs, the firm's operating profits are entirely absorbed by the wage bill of inexperienced entrepreneurs. Then, market clearing for a typical variety produced in region 1 implies:

$$
w_{1, i m}^{S}=\frac{\mu}{\sigma f_{i m}}\left[\frac{L_{1}}{P_{1}^{1-\sigma}}+\frac{L_{2}}{P_{2}^{1-\sigma}} \phi\right]
$$

The price index is also modified and depends now on the number of varieties produced by immobile entrepreneurs:

\footnotetext{
${ }^{29}$ We do not analyse the effect of different regional education costs. In what follows education costs are assumed to be spatially identical.
} 


$$
P_{1}^{1-\sigma}=\frac{L_{1, h}^{S}}{f_{h}}+\phi \frac{L_{2, h}^{S}}{f_{h}}+\frac{L_{1, l}^{S}}{f_{l}}+\phi \frac{L_{2, l}^{S}}{f_{l}}+\frac{\left(1-\alpha_{1}\right) L_{1, i m}^{S}}{f_{i m}}+\phi \frac{\left(1-\alpha_{2}\right) L_{2, i m}^{S}}{f_{i m}}
$$

and

$$
P_{2}^{1-\sigma}=\phi \frac{L_{1, h}^{S}}{f_{h}}+\frac{L_{2, h}^{S}}{f_{h}}+\phi \frac{L_{1, l}^{S}}{f_{l}}+\frac{L_{2, l}^{S}}{f_{l}}+\phi \frac{\left(1-\alpha_{1}\right) L_{1, i m}^{S}}{f_{i m}}+\frac{\left(1-\alpha_{2}\right) L_{2, i m}^{S}}{f_{i m}} .
$$

The general equilibrium of the model combines consumer and producer optimization with education optimization and market clearing conditions to simultaneously solve for location choice of high-skilled and low-skilled workers and to determine the number of newly skilled entrepreneurs in each region. Thus, we have to resolve a system of equations including wages of mobile individuals (8) with new price indices (16) using the location choice condition (10), and with the reward of unskilled entrepreneurs (15) considering the share of unskilled workers $(12)$.

Due to the relative complexity of the model, only numerical simulations are done. Figure (7, panel at the top) plots the endogenous share of newly skilled entrepreneurs in region $1,\left(1-\alpha_{1}\right)$, and in region 2, $\left(1-\alpha_{2}\right)$, with respect to trade liberalization and the associated level of low skilled and high skilled entrepreneurs (panel at the bottom). ${ }^{30}$

The first result (from the diagram at the bottom representing location's choice), is that there is no longer dispersion of high skilled entrepreneurs with a spatial sorting for high trade costs as in the previous section. The introduction of new entrepreneurs induces an agglomeration of high skilled and low skilled entrepreneurs for high trade costs. Indeed, mobile people are already agglomerated at autarky. This confirms Okubo's result (2010) that heterogeneity is an agglomeration force for high trade costs.

Furthermore, for these levels of trade costs, the share of new entrepreneurs is high in the peripheral region (panel at the top). This is a significant result: it means that there are opportunities to produce local varieties at the periphery that are not exploited by mobile entrepreneurs who benefit from an agglomeration rent in the core.

With trade integration, the number of unskilled workers who invest in learning and launch a firm dramatically falls. Trade integration foster competition and reduces the wage of immobile entrepreneurs at the periphery. In contrast, investment in education increase in the core where the rate of firm creation overpasses that of the periphery for intermediate levels of trade costs. Deeper integration generates divergence with an advantage in terms of market size for the core. The geography of education becomes increasingly uneven until the critical point at which

\footnotetext{
${ }^{30}$ Parameters: $\sigma=3, \beta=1, L_{i m}=4, \mu=0.9, f_{i m}=1.5, f_{l}=1, f_{h}=2, \gamma=0.1$.
} 
low-skilled workers start to flee the core.

But the migration of low-skilled workers who progressively leave the core has a beneficial effect on education at the periphery. Indeed this relocation and better access to markets thanks to trade liberalization, increase the profits of local entrepreneurs at the periphery which fuels education investment. Then, during the process of partial dispersion, there is a definitive phase of convergence in the number of firms created by local entrepreneurs.

Figure 7: Location choices with respect to trade costs

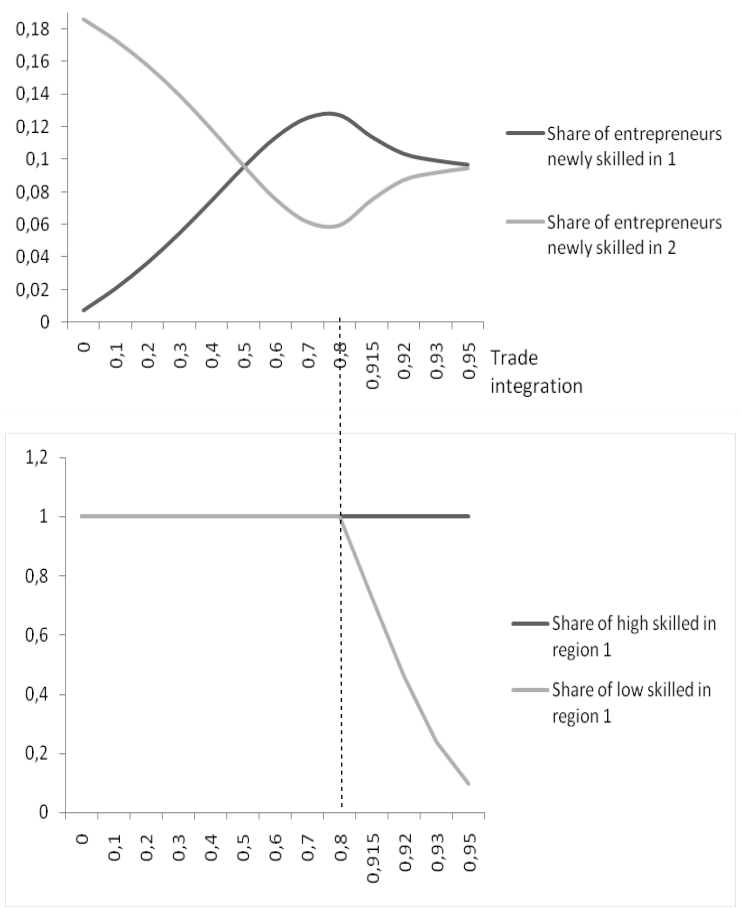

Therefore, regarding education, we retain the following result. ${ }^{31}$

Result 1 Under full agglomeration and trade integration the share of firms created by local entrepreneurs is increasing in the large region and decreasing in the small one but a process of convergence occurs for the lower level of trade costs and partial dispersion of skills.

By treating unskilled workers as individuals who lack the ability to create a firm in the modern sector, core-periphery models find a phase of trade liberalization in which the periphery is totally specialized in a traditional sector. Here, even when agglomeration occurs, the peripheral region still produces varieties, however the trend towards specialization is verified. Regional trade integration which is often viewed as a public policy favoring the periphery is in fact detrimental in terms of local production even by considering firms that are not footloose. Only a low level of trade costs allows fostering convergence.

\footnotetext{
${ }^{31}$ We offer a result instead of a proposition because part of the proof is based on simulations. We have conducted various robustness checks to ensure that similar examples exist with different parameters.
} 


\section{$5 \quad$ Empirical evidence}

The theoretical developments have stressed the role of trade in the spatial sorting of skills within a territory. In particular, as trade is liberalized, high-skilled workers agglomerate in core regions while lower skilled workers remain at the periphery. As discussed in section 3.5, empirical studies are quite scarce but confirm these theoretical predictions, at least in emerging markets and industrialized countries by the past. To reinforce our results and deepen this investigation, we proceed to an analysis of the determinants of distribution of skills in the U.S. focusing on the role of integration. Two experiments are conducted, one on the basis of historical data coinciding with the massive integration of the United States, the other based on more current data, namely from 1997 to 2007 . We aim to determine whether trade still influences the distribution of educated workers in each U.S. state. The choice of the United States has been done for many reasons linked to our assumptions (and to the data availability): individuals are mobile (at least more than in Europe), the country is characterized by a considerable diversity of its territory and by divergence in skills levels (Moretti, 2012). After presenting the historical perspective, the contemporary analysis is presented with a specific section devoted to database construction.

\subsection{Historical perspective}

A historical perspective is first adopted by working on the post-war period (1940-1960). Basing this on decennial censuses and national highway statistics, we can analyse the causal relation between the distribution of skills among U.S. states and the process of domestic integration. With particular concern for data availability, especially at the state level, we use state truck registrations to capture the domestic integration of each state. As underlined by Michaels (2008), trucks are the primary mode for domestic trade flows as highways are built. The author showed in particular a strong positive correlation between highways, trade and commuting. He came to the conclusion that by increasing trade and commuting, highways raised the relative demand for skills in countries with an initially high endowment of human capital. Compared to Michaels, we analyse the impact of trade integration of the distribution of skills for a former period, one before the Interstate Highway System was completed in 1975. As a contrast, we choose the post-war period as it coincides with a huge process of integration. Since the early $1920 \mathrm{~s}^{32}$, the road network has been considerably developed. For instance the first superhighway, the Pennsylvania turnpike, opened in 1940. This has led to a situation, at the end of the war in which each state was linked with the others, fostering the domestic integration of the country.

\footnotetext{
${ }^{32}$ Congress allocated 20 million a year to improve road infrastructure, with the Federal Aid Road Act of 1916
} 
We work at the state level which is the spatial unity that provides us the minimum level of data to conduct our investigation. The proportion of high- skilled workers, measured by educational attainment ${ }^{33}$-in tertiaty education- from the decennial censuses of 1940, 1950 and 1960, is regressed on truck registrations, by controlling for mileage of roads, internal distance, state heterogeneity and time effects. As mentioned above, truck registrations at the state level are provided by the national highway statistics, as the mileage of public roads. Internal distances are built by following Head and Mayer's (2000) formula. ${ }^{34}$

Table 1: Descriptive Statistics 1940-1960

\begin{tabular}{l|cccc}
\multicolumn{1}{c}{} & Mean & Std Deviation & Min & Max \\
\hline Skilled workers (educational attainment) & 4.122 & 1.432 & 1.709 & 7.392 \\
Skilled workers in log & 1.462 & 0.315 & 0.812 & 2.000 \\
Trucks registrations & 116418.16 & 95002.97 & 2417 & 431319 \\
Trucks registrations in log & 11.296 & 0.989 & 7.790 & 12.794 \\
Mileage of public roads & 58.62 & 9.03 & 11.73 & 99.02 \\
Mileage in log & 4.07 & 2.20 & 2.46 & 4.59 \\
Internal distance & 99.30 & 56.78 & 15.86 & 212 \\
Internal distance in log & 4.59 & 4.03 & 2.76 & 5.35 \\
\hline
\end{tabular}

Table 2 reports the results of OLS regressions, in which the dependent variable is the share of skilled workers (who have attained tertiary education). Column 1 presents the coefficient of a bivariate regression, which only concerns the log of truck registrations. It is positive and statistically different from 0 at the $1 \%$ level. This result goes in the direction of a positive effect of trade integration on the proportion of skilled workers. The more a state is integrated the more it attracts skills. This result is robust to the introduction of various controls. Indeed, Column 2 reports the estimates when the mileage of roads and internal distance are introduced. Roads seem to positively affect the proportion of skilled workers, going in the same direction, while distance presents a negative (but insignificant) sign. These parameters confirm that trade integration fosters the concentration of skills. In column 4, state- and time-specific fixed effects are used without alteringing prior results. It is noteworthy that the truck registrations' coefficient decreases when controls are involved but stays statistically significant. Finally, we can suspect a multicollinearity between mileage of roads and internal distance and in fact when mileage is deleted then internal distances present a significant coefficient. The interaction term is itself not significant.

\footnotetext{
${ }^{33}$ Data on educational attainment by state and year comes from the U.S. Census Bureau. Two kinds of skills are distinguished: low- and high- skilled workers, according to educational attainment in secondary (highschool degree) and tertiary education (bachelor degree or more).

${ }^{34}$ The internal distance is obtained with the following expression $d_{i}=(2 / 3) \sqrt{A_{i} / \pi}$ with $A_{i}$ the state area.
} 
Table 2: Trade and skills: historical results 1940-1960

\begin{tabular}{l|ccccc}
\multicolumn{1}{c}{$(1)$} & $(2)$ & $(3)$ & $(4)$ & $(5)$ \\
\hline Truck registrations & 0.862 & 0.689 & 0.350 & 0.350 & 0.310 \\
& $(0.109)^{a}$ & $(0.097)^{a}$ & $(0.109)^{a}$ & $(0.109)^{a}$ & $(0.105)^{a}$ \\
Mileage of public roads & & 0.289 & 0.201 & & \\
& & $(0.065)^{a}$ & $(0.095)^{b}$ & & \\
Internal distance & & -0.080 & -0.049 & -0.210 & \\
& & $(0.091)$ & $(0.089)$ & $(0.122)^{b}$ & \\
Distance*roads & & & & & 0.123 \\
& & & & & $(0.091)$ \\
\hline Controls (time/state) & No & No & Yes & Yes & Yes \\
Adjusted-R & 0.21 & 0.38 & 0.92 & 0.92 & 0.90 \\
Observations & 192 & 192 & 192 & 192 & 192 \\
${ }_{a, b}{ }^{2}$ signify at the $1 \%$ and $5 \%$ level of significance. & & &
\end{tabular}

A striking result of Table 2 is that truck registrations alone explains approximately $21 \%$ of the total variation in the proportion of skilled workers. Furthermore, according to our preferred estimation (Column 4), doubling truck registrations leads to increase the share of skilled workers by $35 \%$. It is noteworthy that this result is obtained by taking into account differences in initial education levels and unobserved time-specific effects affecting all individuals in the same way such as technical changes between years 1940, 1950 and 1960 which are partly captured by time-specific fixed effects.

Keeping in mind that the share of skilled was weak at that time (the average share of skilled workers between 1940 and 1960 was equal to 4.12\%) this result helps to grasp how a better domestic market access has contributed to the strong growth of the proportion of skilled workers in the United States after 1960.

\subsection{Does trade still influence the spatial sorting of skills? A contemporary empirical analysis}

The previous historical analysis has obvious limitations, it does not allow us to check the robustness of results due to data availability on trade integration and domestic market access. That period is also problematic to obtain alternative controls such as wages or past levels of skills. This lack of data prevents us from using alternative measures of trade and methods such as an instrumentation strategy to address a potential reverse causality. As a result we decide to adopt a second perspective, aimed at analysing the impact of trade on the distribution of skills in the contemporary era, more precisely between 1997 and 2007. To deepen our analysis we decide to build a market access index at the state level, from a trade gravity equation (Redding and Venables, 2004). This measure has already been employed by Redding and Schott (2003) to assess the role of trade on education at the world scale, showing a positive effect of market 
integration on educational attainments. Our approach differs substantially from theirs as we work at the regional level, and to our knowledge no market access indicator has been built on this scale. ${ }^{35}$ A robustness check, an alternative measure of trade integration have been built and used in the estimations, based on Anderson and Yotov (2010) who propose a structural estimation of multilateral trade costs. Once, these trade indicators built, we are able to estimate the effect on the proportion of skilled workers in each state. A first subsection is devoted to data description and the second to the empirical strategy and results.

\subsubsection{Data}

Noting that trade barriers, especially domestic ones, are not observable and therefore not directly measurable, efforts are concentrated on indirect measures built with the registered trade flows. Both measures chosen, namely market access (Redding and Venables, 2004) and multilateral trade resistances (Anderson and Yotov, 2010), are initially based on an estimate of the Anderson and van Wincoop's well-known gravity equation (2003). The former consists in using the predicted values of state-specific fixed effects to build market and supplier access indexes while the latter is based on a structural estimation of the non-linear system of equations peculiar to the Anderson and van Wincoop theoretical development. A detailed description is provided in the appendices.

The novelty here is that these trade measures are built at the regional level, by combining intraregional, inter-regional and international trade flows. Combining domestic trade flows with international trade flows from U.S. states has been previously attempted by Coughlin and Novy (2011). Wolf (2000) and Millimet and Osang (2007) work with US intranational trade, but they do not precisely analyse international trade. This procedure involves raising an important issue, namely combining different data sets from different sources. Turning thus towards the data, 48 U.S. states are represented for the years 1997, 2002 and 2007 and the largest U.S. export foreign destinations. Data on inter- and intrastate trade flow comes from the U.S. Commodity Flow Survey (CFS) collected by the U.S. Department of Transportation ${ }^{36}$. Trade between U.S. states and foreigner partners comes from the Origin of Movement series ${ }^{37}$ compiled by the Foreign Trade Division of the U.S. Bureau of the Census. ${ }^{38}$

It is important to underline that the CFS trade data does not include agricultural and some mining products whereas the Origin of Movement series includes all products. To improve the

\footnotetext{
${ }^{35}$ An exception is the study of Coughlin and Novy (2013) in which authors build an indirect measure of domestic trade barriers of the United States based on interstate trade flows.

${ }^{36} \mathrm{http}: / /$ www.bts.gov/publications/commodity_flow_survey/

${ }^{37}$ See Cassey (2009) who provides an in-depth discussion of this database.

${ }^{38}$ http://www.wisertrade.org/home.
} 
comparability of the two sources of data, we follow Anderson and van Wincoop (2003) and Coughlin and Novy (2011) and rescale the data in the CFS by the ratio of total merchandise trade to total domestic shipments reported in the CFS database. It is necessary to introduce international trade (trade between other foreign countries, partners of the U.S. states) because a decrease in trade costs between two foreign countries can have network effects that influence U.S. states. These are available from the U.N. Comtrade database.

Furthermore, trade within each foreign country is computed from Wei's formula (1996). For this, we use the STAN database to obtain productions and shipment-to-value added ratios for OECD partners.

Then, as described in the appendices, a bilateral trade cost function is at work in the gravity equation. We need to compute all bilateral distances that separate each origin and destination. While common distances between countries are available from the CEPII, distances between U.S. states and between each state and foreign countries are computed using the World Gazetteer database for latitude, longitude and population. ${ }^{39}$ Bilateral distances between the main cities of each state and country ${ }^{40}$ are calculated following the great circle formula, ${ }^{41}$ and then aggregated by the population of these cities. To complete trade costs, dummy variables reflecting borders are included. We consider real borders i.e. contiguity, which takes a value of 0 when there are no trade flows. The coefficient of this dummy varies from 22 to 3 , depending on the controls (see respectively McCallum, 1995; Behrens, Erthur and Koch, 2007) and is not central in our study, where 0 trade flows are taken into account with PPML and where fixed effects already control for countries ' characteristics. Using American data at the state level, Millimet and Osang (2007) show that this border effect is almost eliminated when past trade is taken into account. Thus we follow this strategy of using lagged trade as a robustness check. In addition, to construct the market potential measure of Harris, we use U.S. states' GDPs from the U.S. Bureau of Economic Analysis ${ }^{42}$ and foreign countries' GDPs from World Development Indicators.

Finally, after constructing the different variables of trade integration, we turn to the second step of our empirical analysis, which consists in estimating the trade effect on the spatial distribution of skills. Data on educational attainment defined by state and year comes from the U.S. Census Bureau. ${ }^{43}$ Two kinds of skills are distinguished: low- and high- skilled workers, according to educational attainment in secondary (highschool degree) and tertiary education (bachelor degree or more).

\footnotetext{
${ }^{39} \mathrm{http}: / /$ world-gazetteer.com/.

${ }^{40}$ Cities with more than 100000 people are taken into account in each state and country.

${ }^{41}$ http://mathworld.wolfram.com/GreatCircle.html.

${ }^{42}$ http://www.bea.gov/regional/index.htm.

${ }^{43}$ http://www.census.gov/hhes/socdemo/education./
} 
Table 3: Descriptive statistics

\begin{tabular}{llcccc} 
& & Mean & Std Deviation & Min & Max \\
\hline Highschool attaintment & level & 84.55 & 4.02 & 75.40 & 92.20 \\
& logistic transformation & 1.73 & 0.30 & 1.12 & 2.46 \\
Bachelor and more attaintment & level & 25.32 & 4.81 & 14.60 & 37.90 \\
& logistic transformation & -1.09 & 0.25 & -1.76 & -0.49 \\
Market access & level & 0.02 & 0.06 & 0.00002 & 0.44 \\
Multilateral trade & log & -5.24 & 1.67 & -8.22 & -0.82 \\
High-skilled wages & level & 5.48 & 0.28 & 4.98 & 6.13 \\
Low-skilled wages & log & 2.20 & 0.11 & 1.88 & 2.48 \\
\multirow{2}{*}{ Population } & level & 48899.06 & 10276.03 & 33422.35 & 88513.70 \\
Economic growth per capita & logel & 10.98 & 0.17 & 10.66 & 11.37 \\
& log & 26628.66 & 4850.02 & 18040.08 & 37106.17 \\
& level & 10.47 & 0.18 & 10.14 & 10.86 \\
& & 6.05 & 6.075 & 0.56 & 37.25 \\
& & 0,05 & 0,023 & $-0,001$ & 0,13 \\
\hline
\end{tabular}

\subsubsection{Results}

This section aims at quantifying the effects of trade on the proportion of skilled workers. Table 4 reports the results of regressing the proportion of skilled workers on market access and various controls. Because the proportion of the educated population is bound to 1, we employ a logistic transformation (as suggested by Redding and Schott, 2004). The econometric model can be written as follows

$$
\ln \left(\frac{L_{S_{i t}}}{1-L_{S_{i t}}}\right)=\alpha_{0}+\alpha_{1} \ln \left(\widehat{\phi}_{i t}\right)+\mu_{i}+\mu_{t}+Z_{i t}+\varepsilon_{i t},
$$

where $L_{S_{i t}}$ represents the proportion of skilled workers in the population, defined by state and expressed in its logistic transformation. Two kinds of skilled workers are alternatively considered, according to educational attainment (low-skilled workers have reached the high school and started their tertiary education, while high-skilled ones have attained a bachelor's degree and more). Table 4 reports the estimated coefficients for each. The variable $\widehat{\phi}_{i t}$ refers to trade integration (market access or multilateral trade costs), $Z_{i t}$ is a vector of additional controls, including wages of each kind of workers, total population, and the growth of income per capita. The variables denoted $\mu_{i}, \mu_{t}$ are state- and time- specific effects. 
Table 4: The effects of trade integration on skills, 48 U.S. states 1997-2007

\begin{tabular}{|c|c|c|c|c|c|c|c|}
\hline & \multicolumn{4}{|c|}{ High-skilled } & \multicolumn{3}{|c|}{ Low-skilled } \\
\hline & (1) & (2) & (3) & (4) & (5) & (6) & (7) \\
\hline Market access & $\begin{array}{c}0.177 \\
(0.044)^{a}\end{array}$ & & & & & & \\
\hline Multilateral trade & & $\begin{array}{c}0.985 \\
(0.171)^{a}\end{array}$ & $\begin{array}{c}0.972 \\
(0.169)^{a}\end{array}$ & $\begin{array}{c}0.975 \\
(0.171)^{a}\end{array}$ & $\begin{array}{c}0.201 \\
(0.095)^{b}\end{array}$ & $\begin{array}{c}0.195 \\
(0.099)^{b}\end{array}$ & $\begin{array}{c}0.178 \\
(0.070)^{b}\end{array}$ \\
\hline High-skilled wages & & & $\begin{array}{c}0.772 \\
(0.083)^{a}\end{array}$ & $\begin{array}{c}0.802 \\
(0.075)^{a}\end{array}$ & & & \\
\hline Low-skilled wages & & & & & & $\begin{array}{c}0.826 \\
(0.109)^{a}\end{array}$ & $\begin{array}{c}0.566 \\
(0.067)^{a}\end{array}$ \\
\hline Population & & & & $\begin{array}{c}0.150 \\
(0.062)^{a}\end{array}$ & & & $\begin{array}{c}0.161 \\
(0.078)^{b}\end{array}$ \\
\hline $\begin{array}{l}\text { Economic growth } \\
\text { (per capita) }\end{array}$ & & & & $\begin{array}{c}0.310 \\
(0.070)^{a}\end{array}$ & & & $\begin{array}{c}0.303 \\
(0.067)^{a}\end{array}$ \\
\hline Adjusted $\mathrm{R}^{2}$ & 0.85 & 0.86 & 0.88 & 0.88 & 0.86 & 0.87 & 0.88 \\
\hline Observations & 141 & 141 & 141 & 141 & 141 & 141 & 141 \\
\hline
\end{tabular}

Table displays OLS coefficients and Huber-White robust standard errors are reported.

Each second-stage regression contains state- and time-specific fixed effects. .

The dependent is a logistic transformation of educational attainment.

Market access is used and replaced by the multilateral resistances (see the text)

${ }^{a, b}$ signify at the $1 \%$ and $5 \%$ level of significance.

The first column reports the estimated coefficient for market access built in a prior step. It is positive and statistically significant at the $1 \%$ level. This means that a state which benefits from a better access attracts more high-skilled workers. Trade seems to affect positively the number of skills at the regional scale. Market access is now replaced by multilateral trade integration based on a structural estimation of the Anderson and van Wincoop's gravity system. Column 2 reports its coefficient which is positive and significant. The same conclusion can be drawn: trade openness positively impacts the proportion of skilled workers at the regional scale. Then, additional time-varying controls are introduced, namely the mean value of wages (defined by skill and state), the level of population and the economic growth rate (of GDP per capita) also measured at the state level. These variables do not affect the main results regarding trade effects. All coefficients are significantly positive, which allows us to confirm the robustness of our prior results. What about less-skilled workers? Columns (5), (6) and (7) reports the same coefficients but for low-skilled workers. The sign of multilateral trade integration is statistically less significant ( $5 \%$ level). Compared to the first results, this goes in the direction of a lower ability to bear the cost of living implied by liberalization. Other coefficients are coherent with prior conclusions.

Some improvements can now be made in the econometric treatment. First, the autocorrelation of the proportion of skills can be treated by introducing past values of education. 
Second the potential endogeneity of trade integration (especially due to reverse causality) has to be controlled. That is why we proceed to two additional sets of regressions. Past levels of educational attainment are first introduced into the estimations. Then, a double-step strategy is applied: transportation infrastructures are used in an instrumentation strategy to resolve these endogeneity problems. The main issue is to find a suitable instrument for transportation infrastructure, allowing us to identify the key parameters in our model. Two main instrumental variables (IV) strategies are reported in the existing literature: the use of planned routes, considered as a quasi-random variation in the observed infrastructures ${ }^{44}$ and historical routes, ${ }^{45}$ based on very old transportation routes also considered as a quasi-random variation (Redding and Turner 2014). ${ }^{46}$ Our choice fell on historical roads, precisely in 1950, since factors that affected the old network of roads do not directly affect economic activity in U.S states, but also because they reflect more trade integration between states than planned routes. So, the log of multilateral trade integration is regressed on the log of historical routes, namely recorded in 1950, and on temporal effects.

Table 5 reports this last set of regressions, including the first step coefficient estimates for IV regressions.

\footnotetext{
${ }^{44}$ Baum-Snow (2007), Michaels et al. (2012) use the 1947 plan of the interstate highway system.

${ }^{45}$ Duranton and Turner $(2011,2012)$

${ }^{46} \mathrm{~A}$ third appraoch is described by authors, the inconsequential place approach, which consists in analyzing networks which have accidentally benefited from infrastructure investments, as in Chandra and Thomson (2000).
} 
Table 5: Trade and skills, auto-correlation and endogeneity

\begin{tabular}{|c|c|c|c|c|c|}
\hline & \multicolumn{3}{|c|}{ High-skilled } & \multicolumn{2}{|c|}{ Low-skilled } \\
\hline & (1) & $(2)$ & $(3)$ & (4) & (5) \\
\hline & OLS & OLS & IV & OLS & IV \\
\hline Market access & $\begin{array}{c}0.144 \\
(0.066)^{b}\end{array}$ & & & & \\
\hline Multilateral trade & & $\begin{array}{c}0.614 \\
(0.069)^{a}\end{array}$ & $\begin{array}{c}0.344 \\
(0.067)^{a}\end{array}$ & $\begin{array}{c}0.284 \\
(0.068)^{a}\end{array}$ & $\begin{array}{c}0.159 \\
(0.065)^{b}\end{array}$ \\
\hline $\begin{array}{l}\text { Past level of skills } \\
\text { (for the year 1987) }\end{array}$ & $\begin{array}{c}0.412 \\
(0.067)^{a}\end{array}$ & $\begin{array}{c}0.461 \\
(0.072)^{a}\end{array}$ & $\begin{array}{c}0.459 \\
(0.075)^{a}\end{array}$ & $\begin{array}{c}0.284 \\
(0.068)^{a}\end{array}$ & $\begin{array}{c}0.217 \\
(0.072)^{a}\end{array}$ \\
\hline Population & $\begin{array}{c}0.244 \\
(0.066)^{a}\end{array}$ & $\begin{array}{c}0.160 \\
(0.064)^{b}\end{array}$ & $\begin{array}{c}0.188 \\
(0.074)^{a}\end{array}$ & $\begin{array}{c}0.144 \\
(0.066)^{b}\end{array}$ & $\begin{array}{c}0.128 \\
(0.067)^{b}\end{array}$ \\
\hline $\begin{array}{l}\text { Economic growth } \\
\text { (per capita) }\end{array}$ & $\begin{array}{c}0.196 \\
(0.067)^{a}\end{array}$ & $\begin{array}{c}0.301 \\
(0.065)^{a}\end{array}$ & $\begin{array}{c}0.260 \\
(0.064)^{a}\end{array}$ & $\begin{array}{c}0.201 \\
(0.095)^{b}\end{array}$ & $\begin{array}{c}0.137 \\
(0.126)\end{array}$ \\
\hline First stage statistics $\left(\mathrm{R}^{2}\right)^{*}$ & & & 0.33 & & 0.33 \\
\hline Over-id p-value & & & 0.198 & & 0.198 \\
\hline Historical routes $(\mathrm{m})$ & & & $\begin{array}{c}0.298 \\
(0.064)^{a}\end{array}$ & & $\begin{array}{c}0.298 \\
(0.064)^{a}\end{array}$ \\
\hline Adjusted $\mathrm{R}^{2}$ & 0.91 & 0.90 & 0.88 & 0.88 & 0.89 \\
\hline Observations & 141 & 141 & 141 & 141 & 141 \\
\hline
\end{tabular}

Table displays OLS coefficients and Huber-White robust standard errors are reported.

Each regression contains state- and time-specific fixed effects

The dependent is a logistic transformation of educational attainment.

*The first stage statistics reported are the within R-squared (variation within countries)

The Overidentification test is based on the Hansen J statitics,

with a null hypothesis that IV are uncorrelated with the error term.

${ }^{a, b}$ signify at the $1 \%$ and $5 \%$ level of significance.

Concerning high-skilled workers both market access and multilateral trade integration keep their positive sign despite the introduction of past values of education and despite the IV strategy. Thus, the effect of trade integration is robust to these alternative econometric treatments. It is noteworthy that past levels of skills explains the current proportion of skilled workers as the sign is strongly significant. All estimates are not reported here, but alternative years have been used (1975, 1987 and 1990) with similar magnitudes. Turning to the IV strategy which consists in using the historical 1950 mileage of public roads to exogenize trade integration, the identification condition is respected as reflected by the Hansen J statistics. Indeed, by looking at the p-values, we easily fail to reject the null hypothesis: the instrument is not correlated with the error term. It is also a reasonable instrument, as we can reject its weakenness, regarding the high significance of its coefficient. The first-stage R-squared reported is a within R-squared which indicates how much of the variation of trade integration is explained by historical routes within countries. Finally, regarding less-skilled workers, the initial conclusions are robust. Multilateral trade integration is significant but of less magnitude for low-skilled workers compared to the high-skilled. 


\section{Conclusion}

The aim of this paper has been to analyze the location choices and the creation of human capital in a period of regional trade integration. We have shown that for intermediate levels of trade integration, agglomeration and creation of human capital occur in the core. However, when trade costs are low, some skilled workers leave the core and convergence is possible in the spatial distribution of skills. A potential policy implication for countries experiencing investment in regional integration is that education at the periphery may be maintained with intermediate trade costs, because convergence arises for deeper integration.

Obviously more research needs to be done to obtain analytical results and to investigate other channels. For instance technological change both in transportation and other sectors have played an important role in the past to explain the spatial economy of developed countries. ${ }^{47}$ In short, New Economic Geography is often presented as a useful static tool to describe the bell-shaped curve of spatial development since the industrial revolution. But over this long period of time, large-scale technological change has been significant and thus one needs to go beyond the current modeling to learn how the race between education and technology has been so critical for the reinvention and resilience of some regions in terms of economic performance.

\section{References}

[1] Allen T (2014) Information Frictions in Trade. Econometrica, 82:2041-2083.

[2] Anderson J, van Wincoop E (2003) Gravity with Gravitas: A Solution to the Border Puzzle. Am Econ Rev 93: 170-192

[3] Anderson J, Yotov Y (2010) The Changing Incidence of Geography. Am Econ Rev 100: 2157-86

[4] Baldwin R, Forslid R, Martin P, Ottaviano G, Robert-Nicoud F (2003) Economic Geography and Public Policy. Princeton U Press.

[5] Bardes S, Peirson J (2010) Non-negativity and agglomeration behavior of the quasi-linear logarithmic model of NEG. Let Spat Res Sci 4: 91-101

[6] Baum-Snow N (2007) Did highways cause suburbanization? Quarterly Journal of Economics 122(2):775-805

\footnotetext{
${ }^{47}$ The need for introducing technological change is summarized by Glaeser et al. (2014):

"Regional and urban change is best understood not as the application of time-invariant growth processes, but rather as a reflection of large-scale technological change. These processes are quite amenable to formal modeling, but only to formal models that respect the changing nature of transportation and other technologies".
} 
[7] Baum-Snow N, Brandt L, Henderson J V, Turner M A, Zhang Q (2011) Roads, railways and decentralization of Chinese cities. WP Brown University.

[8] Baum-Snown N and Feirrera (2015) Causal Inference in Urban and Regional Economics. In: G Duranton, V Henderson, W Strange (eds) Handbook of Urban and Regional Economics.

[9] Behrens K, Duranton G, F Robert-Nicoud (2014) Productive Cities : Sorting, Selection, and Agglomeration. J Polit Econ 122:507-53.

[10] Behrens, K, G Mion, Y Murata, and J Südekum (2013) Spatial frictions. CEPR 8572.

[11] Behrens, K., and Robert-Nicoud, F. (2014) Survival of the Fittest in Cities: Urbanisation and Inequality. Econ J. Published online, doi: 10.1111/ecoj.12099.

[12] Bosker M, Brakman S, Garretsen H, Schramm M (2012) Relaxing Hukou: Increased labor mobility and China's economic geography. J Urban Econ. 72: 252-266

[13] Brülhart M, Traeger R (2005) An Account of Geographic Concentration Patterns in Europe. Reg Sci Urban Econ 35: 597-624.

[14] Burchfield M, Overman H G, Puga D, Turner M A (2006) Causes of sprawl: A portrait from space. Q J Econ 121:587-633.

[15] Caliendo L, Parro F, Rossi-Hansberg E, Sarte P D (2014) The Impact of Regional and Sectoral Productivity Changes on the U.S. Economy. Working Paper.

[16] Candau F (2011) Is Agglomeration Desirable? Annals of Economics and Statistics, 101/102: 203228.

[17] Cassey A (2009) State Export Data: Origin of Movement vs. Origin of Production. J Econ Soc Measur, 34 (4).

[18] Chandra A, Thompson E (2000) Does public infrastructure affect economic activity? Evidence from the rural interstate highway system. Regional Science and Urban Economics 30(4):457-490.

[19] Chaney T (2014) The Network Structure of International Trade. Am Econ Rev 2014, 104: 3600-3634

[20] Combes, P-Ph, G Duranton, L Gobillon (2008) Spatial wage disparities: Sorting matters! J Urban Econ 63(2):723-742.

[21] Combes P-Ph, G. Duranton, L. Gobillon, D. Puga and S. Roux (2012) The productivity advantages of large cities: Distinguishing agglomeration from firm selection, Econometrica 80 (6), 2543-2594

[22] Combes, P-Ph, G Duranton, L Gobillon, and S Roux (2010) Estimating agglomeration effects with history, geology, and worker fixed effects. In Edward L. Glaeser (ed.) Agglomeration Economics. Chicago, il: Chicago University Press 
[23] Combes P-Ph, Duranton G, Gobillon L, Roux S (2012) Sorting and local wages and skill distributions in France, Reg Sci Urban Econ, 42:913-930.

[24] Combes, P-Ph, Lafourcade, M., Thisse, J-F., Toutain, J-C (2011) The Rise and Fall of Spatial Inequalities in France: A Long-Run Perspective, Explor Econ Hist 48:243-271.

[25] Combes P-Ph and L Gobillon (2015). The Empirics of Agglomeration Economies. In: G Duranton, V Henderson, W Strange (eds) Handbook of Urban and Regional Economics.

[26] Coughlin C, Novy D (2011) Domestic and International Border Effects: State Size Matters. Unpublised paper.

[27] Cronon, W (1992) Nature's metropolis: Chicago and the Great West. WW Norton \& Company.

[28] De La Roca J, G.I.P. Ottaviano and D. Puga (2014) City of Dreams. CEP Discussion Paper No 1305.

[29] Dixit, A (1990) Optimization in Economic Theory. Oxford U Press.

[30] Duranton G, Morrow P and M Turner (2014) Roads and Trade: Evidence from the U.S. Review of Economic Studies, 81(2), 681-724

[31] Duranton G, and M Turner (2011) The fundamental law of road congestion: Evidence from US cities. American Economic Review 101(6):2616-2652.

[32] Duranton G and M Turner (2012) Urban growth and transportation. Review of Economic Studies 79(4):1407-1440.

[33] Eeckhout J, Pinheiro R, Schmidheiny K (2014) Spatial Sorting. J Polit Econ 122:507-53.

[34] Falvey R, Greenaway D, Silva J (2010) Trade liberalisation and human capital adjustment. J Int Econ, 81: 230-239

[35] Forslid R, Ottaviano G (2003) An Analytically Solvable Core-Periphery Model. J Econ Geogr 3: $229-240$

[36] Fujita M, P Krugman A J. Venables (1999) The Spatial Economy: Cities, Regions and International Trade, Cambridge: MIT Press.

[37] Ghani E, A Grover Goswami, W R. Kerr (2012) Highway to success: The impact of the Golden Quadrilateral project for the location and performance of Indian manufacturing. Working Paper 18524, National Bureau of Economic Research.

[38] Ganong P, Shoag, D (2012) Why Has Regional Convergence in the U.S. Stopped? Harvard Working Paper.

[39] Glaeser E.L (2005.a) Reinventing Boston: 1640-2003, J Econ Geogr, 5(2) (2005): 119- 153 
[40] Glaeser E.L (2005.b) Urban Colossus: Why New York is America's Largest City, Fed Res Bank New York Econ Pol Rev 11: 7-24.

[41] Glaeser E L., J E. Kohlhase, 2004, Cities, regions and the decline of transport costs. Papers Reg. Sci. 83, 197-228.

[42] Glaeser E.L., Ponzetto, A.M., and Tobio, K. (2014). Cities, Skills and Regional Change. Reg Stud, $48: 7-43$.

[43] Glaeser E L, Rosenthal S, Strange W (2010) Urban Economics and Entrepreneurship. J Urban Econ, 67: 1-14.

[44] Goldin C., Katz L. (2008) The Race between Education and Technology. Belknap Press.

[45] Head K, Mayer T (2000) Non-Europe: The Magnitude and Causes of Market Fragmentation in the EU. Rev World Econ, 136: 284-314

[46] Head K, Mayer T (2013) What separates us? sources of resistance to globalization. Can J Econ 46:1196-1231.

[47] Helsley, R W. and W C. Strange (1990) Matching and agglomeration economies in a system of cities. Reg Sci Urban Econ 20(2):189-212.

[48] Helpman, E. (1998). The size of regions. In: D. Pines, E. Sadka, and I. Zilcha (eds.). Topics in Public Economics. Theoretical and Empirical Analysis. Cambridge, Cambridge U Press. 33-54.

[49] Irarrazabal, A., Moxnes, A., Ulltveit-Moe, K.H. (2013) Heterogeneous firms or heterogeneous workers? Implications for the exporter premium and the impact of labor reallocation of productivity. Rev Econ Stat 95:839-849

[50] Krugman, P. (1991) Increasing returns and economic geography. J Polit Econ 99:483-499

[51] Krugman P, Livas-Elizondo R (1996) Trade policy and the third world metropolis. J Dev Econ 49:137-150.

[52] Michaels, G. (2008) The Effect of Trade on the Demand for Skill - Evidence from the Interstate Highway System. Rev Econ Stat 90:683-701.

[53] Mion G, Naticchioni P (2009) The spatial sorting and matching of skills and firms. Can J Econ, 42: $28-55$

[54] Millimet, D., Osang, T. (2007), Do State Borders Matter for U.S. Intranational Trade? The Role of History and Internal Migration. The Can J Econ, 40:93-126.

[55] Moretti, E. (2012) The new geography of jobs. Houghton Mifflin Harcourt, Boston.

[56] Mori, T, A Turrini (2005) Skills, agglomeration and segmentation. Eur Econ Rev 49 201-225. 
[57] Murata Y, Thisse J-F (2005) A simple model of economic geography à la Helpman-Tabuchi. J Urban Econ, p. 137-155.

[58] Okubo, T. (2010) Firm Heterogeneity and Location Choice. DP 11, RIEB Kobe University.

[59] Ottaviano G (2012) Agglomeration, trade and selection, Reg Sci Urban Econ 42: 987-997.

[60] Pflüger M, Südekum J (2008) Integration, Agglomeration and Welfare. J Urban Econ, 63: 544-566

[61] Redding S, Schott P (2004) Distance, Skill Deepening and Development: Will Peripheral Countries Ever Get Rich? J Dev Econ 72: 515-541

[62] Redding S, Turner M.A. (2014) Transportation costs and the spatial organization of economic activity. Chapter in progress for the Handbook of Regional and Urban Economics

[63] Redding, S., Venables, A. (2004) Economic geography and international inequality. J Int Econ 62: $53-82$

[64] Robert-Nicoud F. (2005) The structure of simple New Economic Geography models (or, On identical twins). J Econ Geogr, 5: 201-234

[65] Sokoloff K, Khan B Z (1989) The democratization of Invention During Early Industrialization. Evidence from the United States, 1790-1846. NBER 578.

[66] Venables A (2011) Productivity in cities: self-selection and sorting, J Econ Geogr, 11:241-251.

[67] Wei, Shang-Jin (1996). Intra-National versus International Trade: How Stubborn are Nations in global Integration. NBER WP 5531.

[68] Wolf H C (2000) Intranational Home Bias in Trade. Rev Econ Stat, 82: 555-63.

[69] Wrede M (2013) Heterogeneous skills, migration, and commuting. Pap Reg Sci, 92:345-360.

\section{A Stability of symmetry}

After tedious rearrangements, we obtain:

$$
\begin{aligned}
\underline{\phi_{h}^{B}} & =\frac{A_{1}+\varepsilon^{2} A_{2}-4 \sqrt{B}}{C_{1}+C_{2}}, \quad \overline{\phi_{h}^{B}}=\frac{A_{1}+\varepsilon^{2} A_{2}+4 \sqrt{B}}{C_{1}+C_{2}} \\
\underline{\phi_{l}^{B}} & =\frac{A_{1}+A_{2}-4 \sqrt{B}}{C_{1}+\varepsilon^{2} C_{2}}, \quad \overline{\phi_{l}^{B}}=\frac{A_{1}+A_{2}+4 \sqrt{B}}{C_{1}+\varepsilon^{2} C_{2}}
\end{aligned}
$$


with:

$$
\begin{aligned}
A_{1} & =(\sigma-1) \gamma f_{h}^{2}(1+\varepsilon)^{2} \sigma \\
A_{2} & =16 f_{h}^{2} \mu(\sigma-1) \\
B & =f_{h}^{4}(1+\varepsilon)^{2} \mu\left[\mu(1-2 \sigma)^{2}-4 \gamma(\sigma-1)^{2} \sigma\right] \\
C_{1} & =f_{h}^{2}\left(-4 \varepsilon \mu-\left[\gamma(1+\varepsilon)^{2}-8 \varepsilon \mu\right] \sigma+\gamma(1+\varepsilon)^{2} \sigma^{2}\right. \\
C_{2} & =2 f_{h}^{2} \mu(12 \sigma-10)
\end{aligned}
$$

The denominator of $\underline{\phi_{h}^{B}}$ is higher than that of $\underline{\phi_{l}^{B}}$, and the reverse holds for the numerator because $\varepsilon^{2}<1$, and $\underline{\phi_{h}^{B}}<\underline{\phi_{l}^{B}}$. Thus low skilled workers are the first to break the symmetry, and thus:

$$
\underline{\phi^{B}}=\underline{\phi_{h}^{B}}
$$

Identically, $\overline{\phi_{h}^{B}}<\overline{\phi_{l}^{B}}$, which means that dispersion is stable only when it is an equilibrium for high skilled workers, which gives:

$$
\overline{\phi^{B}}=\overline{\phi_{l}^{B}}
$$

To verify that deviation of the h-type at $\underline{\phi_{h}^{B}}$ ( l-type at $\overline{\phi_{l}^{B}}$ ) destabilizes the l-type (h-type), we show:

$$
\begin{aligned}
& \partial \Omega_{l} /\left.\partial L_{h}^{S}\right|_{L_{l}^{S}=L_{h}^{S}=0.5, \phi=\overline{\phi_{h}^{B}}}<0, \text { and } \\
& \partial \Omega_{h} /\left.\partial L_{l}^{S}\right|_{L_{l}^{S}=L_{h}^{S}=0.5, \phi=\overline{\phi_{l}^{B}}}<0
\end{aligned}
$$

if $\gamma<\mu /(\sigma-1)$, and are undefined otherwise.

\section{B Sustain points}

The level of trade costs for which agglomeration is sustainable can be obtained implicitly by equating the indirect utility gap to 0 under full agglomeration. For $\Omega_{i}>0$, type $i$ of workers benefits from an agglomeration rent that renders agglomeration stable in Region 1 . In the following, we refer to "high skilled workers who work in a firm with low fixed costs" as type-l. Two roots are obtained implicitly for workers of type-l (with $L_{1}^{U}=L_{2}^{U}=L^{U}$ ):

$$
\Omega_{l} \equiv \frac{A-B f_{l}}{C}=0
$$


with:

$$
\begin{aligned}
A & =\sum_{i} f_{i} \gamma(\sigma-1) \sigma \phi \log \left[L^{U} /\left(2+L^{U}\right)\right]+\sum_{i} f_{i} \mu \sigma \phi \log \phi \\
B & =\mu(\sigma-1)\left[L^{U}(\phi-1)^{2}+2 \phi(\phi-1)\right] \\
C & =\sum_{i} f_{i}(\sigma-1) \sigma \phi .
\end{aligned}
$$

For h-workers, instead:

$$
\Omega_{h} \equiv \frac{A-B f_{h}}{C}=0
$$

Whatever the level of fixed costs, the welfare differential (agglomeration rent) is bell-shaped with respect to trade liberalization. With $f_{h}=f_{l}$, firms are similar; and Equations (20) and (21) are identical for individuals $h$ and $l$. With $f_{h} \neq f_{l}$, expressions of $\Omega_{h}$ and $\Omega_{l}$ intersect each other if $B=0$, which gives two points of intersections, respectively:

$$
\phi=1, \text { and } \phi=\frac{L^{U}}{L^{U}+2} .
$$

Moreover:

$$
\left.\Omega_{i}\right|_{\phi=1}<0 \text { if } \gamma>0
$$

Finally, the following derivative at the critical point $\phi=1$ can be obtained:

$$
\begin{aligned}
\partial \Omega_{h} /\left.\partial \phi\right|_{\phi=1} & =\frac{\mu\left(f_{l} \sigma+f_{h}(3 \sigma-2)\right)}{\left(f_{h}+f_{l}\right)(1-\sigma) \sigma} \\
\partial \Omega_{l} /\left.\partial \phi\right|_{\phi=1} & =\frac{\mu\left(f_{h} \sigma+f_{l}(3 \sigma-2)\right)}{\left(f_{h}+f_{l}\right)(1-\sigma) \sigma} .
\end{aligned}
$$

To illustrate the analysis, Figure B may help. The welfare differential of each type of workers under agglomeration appears therein (i.e. $\Omega_{l}$ and $\Omega_{h}$ are plotted), with respect to trade liberalization. Agglomeration in Region 1 is stable only when these curves are above the horizontal axis. The following ranking of sustain points is obtained: $\underline{\phi_{h}^{S}}<\underline{\phi_{l}^{S}}<\overline{\phi_{h}^{S}}<\overline{\phi_{l}^{S}}$. 
Figure B: Sustain points

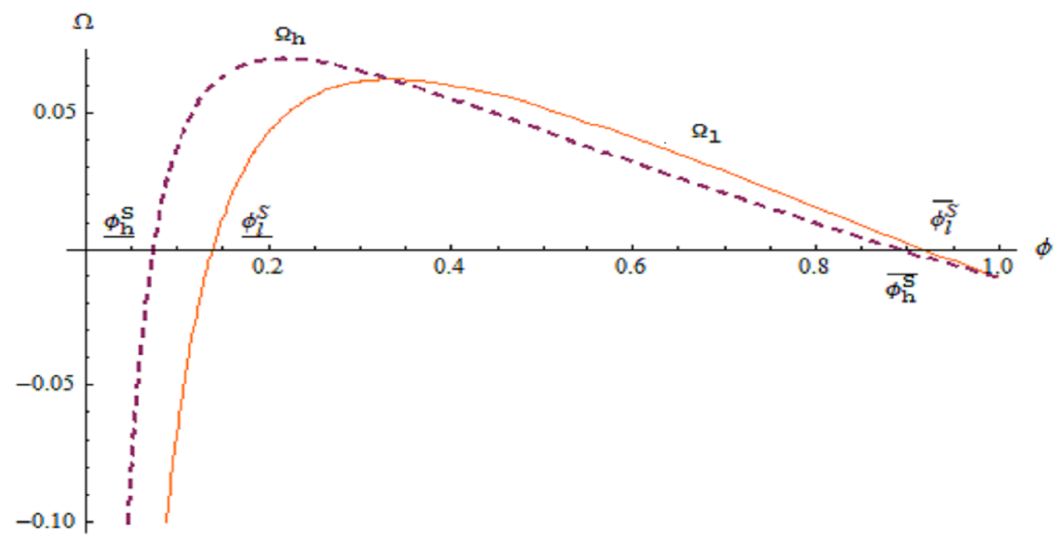

We start by considering the shape of the welfare differential under free trade:

$$
\begin{gathered}
\partial \Omega_{l} /\left.\partial \phi\right|_{\phi=1}=\frac{\mu\left(f_{l} \sigma+f_{h}(3 \sigma-2)\right)}{\left(f_{h}+f_{l}\right)(1-\sigma) \sigma} \\
\partial \Omega_{h} /\left.\partial \phi\right|_{\phi=1}=\frac{\mu\left(f_{h} \sigma+f_{l}(3 \sigma-2)\right)}{\left(f_{h}+f_{l}\right)(1-\sigma) \sigma}
\end{gathered}
$$

The difference between the derivatives in Equations (26) and (27) depends only on the numerator, and because by definition $f_{h}>f_{l}$ and $3 \sigma-2>\sigma(\Leftrightarrow \sigma>1)$, at $\phi=1$, we obtain $\partial \Omega_{l} /\left.\partial \phi\right|_{\phi=1}>\partial \Omega_{h} /\left.\partial \phi\right|_{\phi=1}$. Between points of intersection $\left(\phi \in\left[\frac{L_{i m}}{L_{i m}+2}, 1\right]\right)$, the agglomeration rent of l-type is higher than that of h-type, and because at $\phi=1$, we get negative welfare for everyone in the core $\left.\Omega_{l}\right|_{\phi=1}=\left.\Omega_{h}\right|_{\phi=1}<0$ (under the condition describing the importance of the housing sector from Equation (23)). In turn, the sustain point of trade liberalization is higher for l-type than for h-type. Because the two expressions admit the same asymptote at $\phi=0$ and because welfare differentials are bell-shaped, when trade costs are higher than the point of intersection $\phi=\frac{L_{i m}}{L_{i m}+2}$, the welfare gap of l-type decreases faster that of h-type with increasing trade costs. The sustain point of trade liberalization of l-type is higher than that of h-type. The important implication of this finding indicates that at $\overline{\phi_{l}^{B}}$, workers of h-type gradually start to migrate towards Region 2 (see Figure B; at $\overline{\phi_{l}^{B}}$ there is no agglomeration rent for h-type $\Omega_{h}<0$ ), thus we cannot hold the assumption $L_{r, h}^{S}=1$ that reveals the sustain point of l-type. In other words, the partial dispersion of h-type reduces the price of land, which pushes l-type to stay in Region 1. To prove that l-type resists the dispersion of h-type, we can verify that $\Omega_{l}>0$ that for the whole process of dispersion of h-type. The agglomeration rent of l-type is reduced to 0 only with free trade when all h-type are agglomerated in Region 2 (if 
$L_{r, l}^{S}=0$ and $L_{r, h}^{S}=1$ at $\phi=1$, then $\left.\Omega_{l}=0\right)$. Thus the only $\overline{\phi^{S}}$ is the one of h-type:

$$
\overline{\phi^{S}}=\overline{\phi_{h}^{S}}
$$

This result is new. In search $\underline{\phi^{S}}$, we find the reverse; h-type remains agglomerated and l-type migrates gradually towards Region 2 until full agglomeration is reached (i.e. trade costs increase until autarky, see Figure B). In short:

$$
\underline{\phi^{S}}=\underline{\phi_{l}^{S}}
$$

which matches the result obtained by Okubo (2010).

\section{Bifurcation diagram}

To analyse the robustness of this spatial configuration. We reproduce the methodology presented in the text but in contrast with the simulations done in Figure (1), we consider that low productive firms have higher fixed costs $\left(f_{h}=4\right.$ instead of $\left.f_{h}=2\right)$. Similar results are obtained to those presented previously. The sole difference concerns the stability of perfect dispersion of all workers for high trade costs which is not obtained until $\gamma=0.06$.

Figure 8: Bifurcation diagram

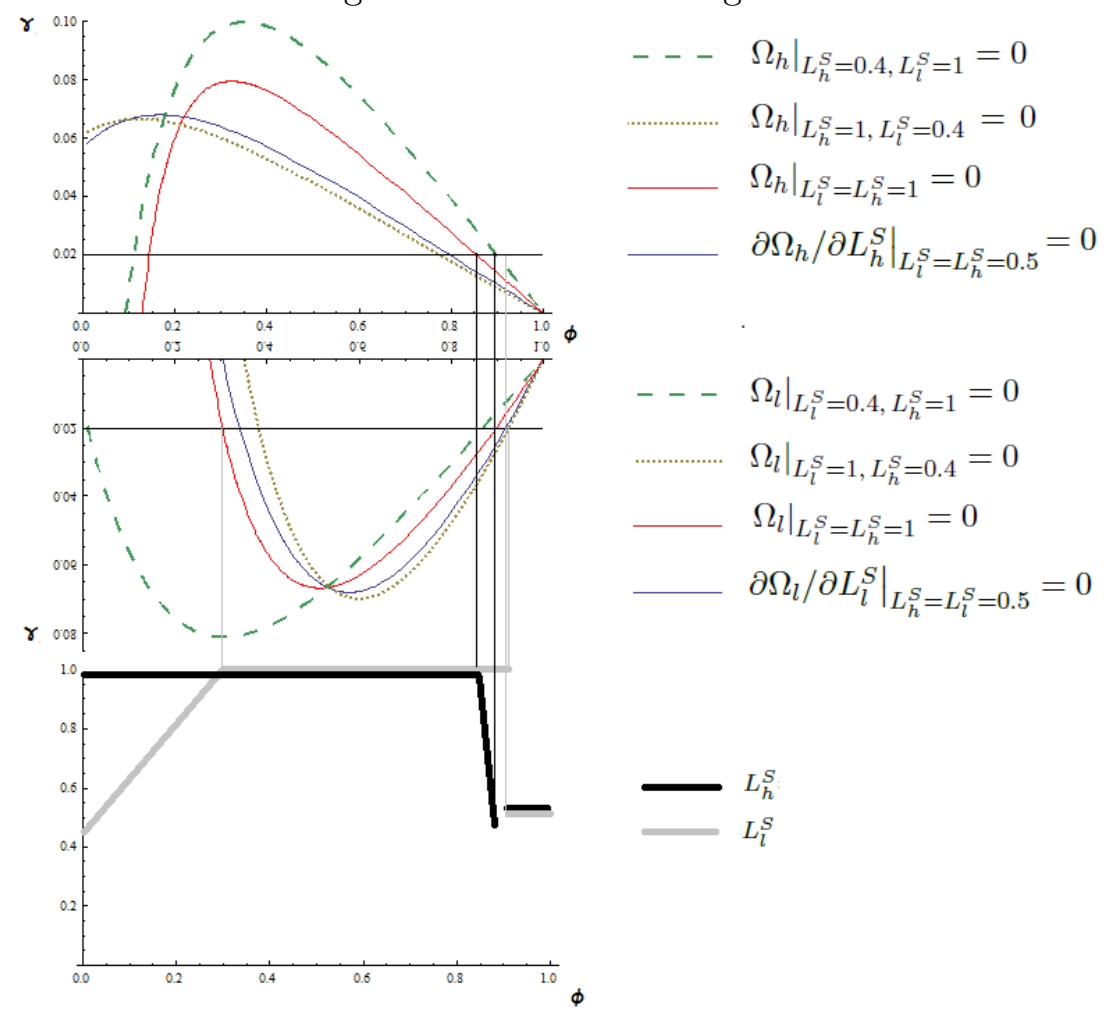

We now analyze what happens when consumer preference for the industrial good is higher. 
We set $\mu=0.9$ (instead of 0.2 ), all other parameters are identical to those used in Figure (1). Figure (9) depicts the loci of $(\gamma, \phi)$ that satisfy equilibria. These new simulations gives the same kinds of results as those obtained in Figure (1). The main difference is that now, with an higher level of industrial goods consumed, agglomeration forces are stronger and thus sustainable for higher preferences regarding housing. For instance we obtained the same tomahawk diagram with $\gamma=0.2$ (while previously we set $\gamma=0.02$ ).

Figure 9: Bifurcation diagram

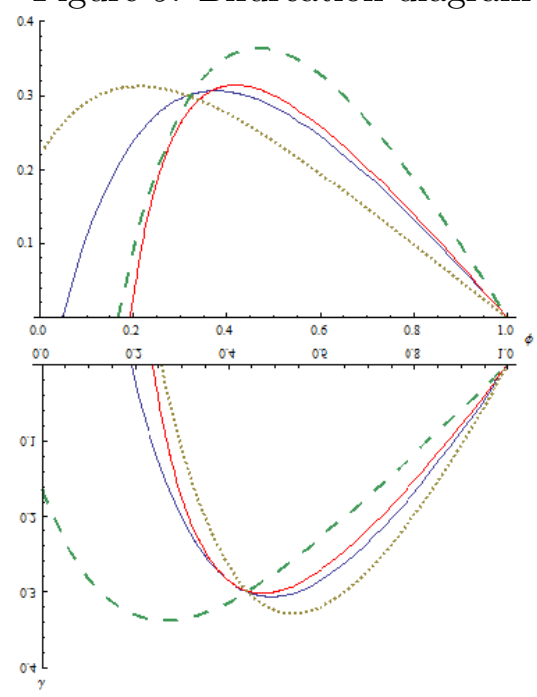

\section{Construction of trade indicators}

\section{Market Access}

The following gravity equation is estimated with a pseudo-maximum likelihood (PPML) estimator ${ }^{48}$ and country-level fixed effects to control for invariant state-specific characteristics:

$$
X_{i j t}=\lambda \ln \phi_{i j}+a_{i} \ln F X_{i}+a_{j} \ln F M_{j}+e_{i j t},
$$

where $F X_{i}$ and $F M_{j}$ are fixed effects to control for each state's market and supply capacity. Predicted values of market access are therefore given by equation (??):

$$
\widehat{\Omega_{i}}=\left[\left(\exp \left(F M_{i}\right)\right)^{\widehat{a_{i}}} \phi_{i i}^{\widehat{\lambda}}\right]+\sum_{j \neq i}\left[\left(\exp \left(F M_{j}\right)\right)^{\widehat{a_{j}}} \phi_{i j}^{\widehat{\lambda}}\right]
$$

\footnotetext{
${ }^{48}$ Following the work of Silva and Tenreyro (2006), the use of pseudo-maximum likelihood estimators (Poisson and derived econometric models) is justified for treating heteroskedasticity and dealing with the presence of zero trade values.
} 
in which $\widehat{a_{i}}, \widehat{a_{j}}, \widehat{\lambda}$ are the parameter estimates of the gravity equation regression. In this equation, bilateral trade costs $\phi_{i j}$ take the following common specification:

$$
\phi_{i j}=d_{i s t_{i j}} \exp \left[Z_{i j}\right]
$$

where $Z_{i j}$ is a vector of dummies characterizing bilateral common borders. Turning to internal trade costs $\phi_{i i}$, we follow Redding and Venables (2004) by expressing the internal trade costs in function of internal distances, computed for a circular country, as follows:

$$
\begin{aligned}
\phi_{i i}^{1-\sigma} & =\operatorname{dist}_{i i}^{\frac{1}{2} \widehat{\lambda}} \\
d_{i s t_{i i}} & =0.66\left(\frac{\text { area }_{i}}{\pi}\right),
\end{aligned}
$$

where $\operatorname{area}_{i}$ is the surface in kms.

\section{Multilateral trade resistances}

Finally, in order to deepen our benchmark specification, we replace market access relying on the two-step procedure of Redding and Venables (2004) with a measure of the outward multilateral resistance term $\left(\Omega_{i}\right)$ following a procedure suggested by Anderson and Yotov (2010). This procedure leads to pursue a structural estimation of the trade flows equation encapsulated in our model. We first estimate the gravity equation using a PPML estimator, which allows obtaining the estimated values of bilateral trade costs $\widehat{\tau_{i j}}$. Then, multilateral resistance terms $\Omega_{i}$ and $P_{j}$ are calculated by resolving the nonlinear system presented above and rewritten here for convenience:

$$
\Omega_{i}=\left(\sum_{j=1}^{R} \frac{Y_{j}}{P_{j}^{1-\sigma}} \widehat{\tau}_{i j}^{1-\widehat{\sigma}}\right)^{1 /(1-\widehat{\sigma})} \text { and } P_{j}=\left(\sum_{i=1}^{R} \frac{Y_{i}}{\Omega_{i}^{1-\sigma}} \widehat{\tau}_{j i}^{1-\widehat{\sigma}}\right)^{1 /(1-\widehat{\sigma})}
$$

This system is resolved by using estimations of $\sigma^{49}$ and setting a country's inward multilateral resistances equal to $1 .^{50}$ All this allows obtaining the outward multilateral trade cost index (OMR) i.e $\Omega_{i}$, which measures the multilateral trade costs borne by sellers ${ }^{51}$.

Thus while the market access obtained previously comes from estimation with country-fixed effects, multilateral trade costs are directly computed from the theoretical model of Anderson and van Wincoop (2003).

\footnotetext{
${ }^{49}$ From Broda, Greenfield and Weinstein (2006) and completed when data is not available.

${ }^{50}$ We are grateful to James E. Anderson for providing Matlab codes for computing the multilateral resistances terms.

${ }^{51}$ while the inward one reflects the buyer incidence of trade costs.
} 